\title{
EVOLUÇÃO DA LEGISLAÇÃO E DAS TÉCNICAS ANALÍTICAS APLICADAS A ESTUDOS DE ESTABILIDADE DE INSUMOS E PRODUTOS FARMACÊUTICOS
}

\author{
Julia Faccia , Luan F. Diniz ${ }^{\mathrm{a}}$, Naialy F. A. Reis ${ }^{\mathrm{a}}$ e Christian Fernandes ${ }^{\mathrm{a}, *, \odot}$ \\ a'Departamento de Produtos Farmacêuticos, Faculdade de Farmácia, Universidade Federal de Minas Gerais, 31270-901 Belo \\ Horizonte - MG,Brasil
}

Recebido em 12/02/2020; aceito em 22/04/2020; publicado na web em 10/06/2020

\begin{abstract}
EVOLUTION OF LEGISLATION AND ANALYTICAL TECHNIQUES APPLIED TO STABILITY STUDIES FOR ACTIVE INGREDIENTS AND PHARMACEUTICAL PRODUCTS. Stability is an important parameter to evaluate the quality, safety and efficacy of drug substances and pharmaceutical products. The stability studies aim to determine the ability of a formulation to maintain its specifications, in order to establish shelf life and recommended storage conditions. Despite the extensive relevance, until the 1980's the stability assessment methods complied with technical and scientific principles without the intervention of regulatory acts by health authorities. The International Council for Harmonisation of Technical Requirements for Pharmaceuticals for Human Use (ICH) establishment in the 1990's boosted the regulation on this issue, not only in the attended countries, but worldwide. In the Brazilian context, the first regulatory norm for stability studies was published in 2002 and it implied the requirement of the submission of a stability report for the sanitary registration of medicines. The development of the Brazilian legislation resulted, among other factors, from the progress of the analytical methods that have become increasingly efficient, sensitive and selective, which allows the achievements of results with greater accuracy and speed; and the use of modern techniques of solid form characterization, which provide important information about the stability of active ingredients and pharmaceutical products.
\end{abstract}

Keywords: legislation; drug stability; analytical methods; pharmaceutical products; stability studies.

\section{INTRODUÇÃO}

A Farmacopeia Brasileira $6^{\mathrm{a}}$ edição $^{1}$ define medicamento como "produto farmacêutico, tecnicamente obtido ou elaborado, que contém um ou mais fármacos e outras substâncias, com finalidade profilática, curativa, paliativa ou para fins de diagnóstico". Já a estabilidade de produtos farmacêuticos é definida pela Organização Mundial da Saúde (OMS) como a capacidade destes manterem as suas características químicas, físicas, microbiológicas e biofarmacêuticas especificadas durante todo o prazo de validade. ${ }^{2}$ Portanto, a avaliação da estabilidade constitui um importante parâmetro para assegurar a qualidade e, consequentemente, a segurança e eficácia dos insumos farmacêuticos ativos (IFAs) e dos produtos farmacêuticos. Neste sentido, os estudos de estabilidade consistem em um conjunto de testes sistematizados que visam não apenas determinar a capacidade de uma formulação manter as suas características, mas também estabelecer o prazo de validade, as condições adequadas de armazenamento e transporte do medicamento e prever a data de reteste dos IFAs. ${ }^{2,3}$ A data de reteste é uma data estabelecida pelo fabricante do IFA com base nos estudos de estabilidade e que, ao ser atingida, deve ser realizada a retestagem do IFA para assegurar que o mesmo se mantém adequado para utilização. ${ }^{3}$

Diversos fatores estão relacionados à estabilidade dos medicamentos, como aqueles relativos à formulação, os fatores intrínsecos e extrínsecos, o processo de fabricação, bem como o material de embalagem e o transporte. Os fatores intrínsecos consistem em interações entre fármacos, interação entre fármaco e excipientes ou solventes, tamanho das partículas, $\mathrm{pH}$ do meio, qualidade da embalagem e condições nas quais o fármaco pode sofrer oxidação, hidrólise ou fotólise. ${ }^{4}$ Por outro lado, os extrínsecos abrangem as condições de estocagem e transporte, nas quais o fármaco pode sofrer alterações devido à temperatura, luz, ar e umidade. ${ }^{4}$

*e-mail: cfernandes@farmacia.ufmg.br
Ainda que os excipientes sejam caracterizados como substâncias inertes, eles são capazes de interagir com outras substâncias, tanto no estado sólido como em solução. ${ }^{5}$ Além disto, a degradação em produtos farmacêuticos frequentemente ocorre em decorrência da reação dos princípios ativos com os excipientes utilizados na formulação. ${ }^{5,6}$ Assim, muitas das reações de incompatibilidade reportadas envolvem hidrólise, oxidação ou interação específica dos princípios ativos com impurezas reativas presentes nos excipientes. ${ }^{5,6}$ Portanto, a presença de traços de impurezas nos excipientes pode afetar a qualidade, segurança e eficácia dos medicamentos, devido à formação de produtos de degradação ativos ou tóxicos, ou à redução da potência do insumo ativo. ${ }^{6}$ Por conseguinte, os estudos de estabilidade são fundamentais para a garantia da saúde dos pacientes, uma vez que a perda de estabilidade dos medicamentos relaciona-se à perda do efeito terapêutico ou à formação de produtos de degradação tóxicos. ${ }^{7}$

A despeito de tamanha relevância, até a década de 1980 os métodos de avaliação da estabilidade seguiam princípios científicos e técnicos sem interferência de atos regulatórios de autoridades sanitárias. Diante disto, tornou-se evidente a necessidade da regulamentação dos parâmetros e métodos para a avaliação da estabilidade. Com a criação, na década de 1990, do comitê denominado The International Council for Harmonisation of Technical Requirements for Pharmaceuticals for Human Use $(\mathrm{ICH})$, por meio da reunião das agências regulatórias do Japão, Estados Unidos e União Europeia, buscou-se regulamentar e harmonizar os atos normativos relacionados à produção e controle de qualidade de medicamentos, incluindo os estudos de estabilidade. ${ }^{8}$

De acordo com a Agência Nacional de Vigilância Sanitária (ANVISA), os estudos de estabilidade são classificados em acelerado, longa duração, acompanhamento, degradação forçada e, mais recentemente, estabilidade pós-reconstituição ou diluição e estabilidade em uso. ${ }^{9} \mathrm{O}$ estudo acelerado requer a utilização de condições forçadas de armazenamento, de modo a acelerar a degradação do produto farmacêutico para avaliar o impacto de exposições rápidas a condições fora do estabelecido, o que pode acontecer durante o transporte, por 
exemplo. ${ }^{10,11} \mathrm{O}$ estudo de longa duração é utilizado para determinar o prazo de validade e as condições de armazenamento adequadas. ${ }^{9,10}$ O estudo de acompanhamento, por sua vez, é realizado após a comercialização do produto, cujo objetivo é verificar se as características previstas nos estudos de estabilidade de longa duração são mantidas. ${ }^{9-11} \mathrm{O}$ estudo de degradação forçada visa promover degradação suficiente que permita a avaliação dos produtos de degradação; para tanto, as condições utilizadas devem ser mais drásticas do que aquelas empregadas no estudo acelerado. ${ }^{10}$ Já o estudo de estabilidade pós-reconstituição ou diluição destina-se a comprovar o período no qual o medicamento mantém estabilidade após a reconstituição, enquanto o estudo de estabilidade em uso é projetado para medicamentos acondicionados em embalagens multidose, cuja finalidade é comprovar que a estabilidade do produto é mantida após a abertura e subsequentes reaberturas da embalagem primária. ${ }^{9}$

A evolução das exigências normativas acerca da estabilidade de insumos e produtos farmacêuticos adveio, dentre outros fatores, do progresso dos métodos analíticos que vêm se tornando cada vez mais eficientes, seletivos e com elevada detectabilidade, permitindo a obtenção de resultados com maior exatidão e rapidez; e do emprego das técnicas de caracterização no estado sólido, que fornecem valiosas informações sobre a estabilidade dos fármacos e dos excipientes em formulações farmacêuticas. Diante disto, o objetivo deste trabalho é apresentar e discutir a evolução dos aspectos legais aplicados à avaliação da estabilidade de IFAs e medicamentos no Brasil e no mundo, bem como traçar um panorama da evolução dos métodos analíticos e das técnicas de caracterização empregadas nessa área.

\section{MÉTODOS}

A pesquisa acerca das legislações foi realizada nos sites da ANVISA, ICH e da Organização Mundial da Saúde (World Health Organization - WHO). Os principais guias relacionados à estabilidade de medicamentos e impurezas, presentes nos sites dessas agências, foram utilizados nessa revisão. A revisão da literatura, para busca de artigos que tratavam de métodos analíticos e de caracterização aplicados aos estudos de estabilidade, foi realizada em bases de dados que fazem parte do portal Periódicos Capes (Web of Science, SciELO, PubMed e SciFinder) utilizando as palavras-chave (em português e em inglês): estudos de estabilidade, insumos farmacêuticos, medicamentos, legislação, espectrofotometria, espectrofotometria derivativa, cromatografia em camada delgada, cromatografia em camada delgada de alta eficiência, cromatografia líquida de alta eficiência, cromatografia líquida de ultra eficiência, cromatografia gasosa, detector ultravioleta, detector de fluorescência, detector por espalhamento de luz evaporativo, detector de aerossol carregado, espectrômetro de massas, difração de raios X, termogravimetria, calorimetria exploratória diferencial, termomicroscopia ótica, espectroscopia vibracional na região do infravermelho, espectroscopia Raman e ressonância magnética nuclear. Nesse momento, não foi objetivo dos autores fazer uma busca exaustiva de todos os artigos que tratassem dessas técnicas, quando aplicadas aos estudos de estabilidade, mas buscar exemplos de técnicas usadas em diferentes períodos, para evidenciar a evolução dessas técnicas como ferramentas para o desenvolvimento de estudos de estabilidade.

\section{HISTÓRICO DA LEGISLAÇÃO}

Os primeiros guias de estabilidade foram publicados na década de 1980, sendo o Japão, Reino Unido, Estados Unidos e a União Europeia os pioneiros. Entretanto, os principais guias acerca deste tema no mundo, os quais são referências para agências regulatórias de diversos países, incluindo o Brasil, são aqueles elaborados pela
WHO e pelo ICH, motivo pelo qual serão abordados neste trabalho. No Brasil, a trajetória da legislação sobre estabilidade de insumos e produtos farmacêuticos foi iniciada em 2002, com a publicação de um guia elementar. ${ }^{12}$ Todavia, nos anos seguintes, novos documentos foram publicados, de modo a tornar a legislação brasileira mais abrangente e similar à internacional. Atualmente, um maior alinhamento da legislação brasileira à legislação internacional será viabilizado devido à conquista da ANVISA de uma vaga no comitê gestor do ICH. A decisão foi tomada pela assembleia do $\mathrm{ICH}$ em reunião realizada no dia 19 de novembro de 2019. ${ }^{13}$

\section{Legislação internacional}

Logo após a sua criação em 1990, o ICH publicou a primeira versão do documento intitulado "Stability testing of new drug substances and products". ${ }^{14}$ Este guia passou por revisões e a que está em vigor foi publicada em 2003. O objetivo deste guia é definir os dados dos estudos de estabilidade que são requeridos para que novos IFAs e medicamentos sejam registrados na União Europeia, Japão e Estados Unidos. A importância dos testes de estabilidade consiste em fornecer informações sobre como a qualidade de um IFA ou medicamento se mantém diante da influência de fatores ambientais como temperatura, luz e umidade, além de fornecer informações sobre o prazo de validade, as recomendações das condições de armazenamento e o estabelecimento do período de reteste para os IFAs. ${ }^{14}$

O mundo é dividido em quatro (I-IV) zonas climáticas, isto é, zonas geograficamente delimitadas segundo critérios de umidade e temperatura. ${ }^{15}$ As condições definidas para os testes deste guia são baseadas nas condições climáticas da União Europeia, Japão e Estados Unidos, os quais abrangem zonas climáticas I e II..$^{14,15} \mathrm{Com}$ isso, as informações sobre estabilidade geradas em cada um desses países, se consistentes com este guia, são mutualmente aceitas entre eles. ${ }^{14}$

O documento aborda os IFAs e os medicamentos separadamente, entretanto, ambos requerem os mesmos tipos de estudos de estabilidade, o acelerado, de longa duração e intermediário, quando apropriado. ${ }^{14} \mathrm{O}$ estudo intermediário consiste na utilização de condições mais brandas do que aquelas utilizadas no estudo acelerado, com duração inferior àquela do estudo de longa duração. ${ }^{14}$ Além disso, este guia aborda também o estudo de estresse ou estudo de degradação forçada (termo adotado pela legislação brasileira). Este estudo é conduzido sob condições severas, a fim de avaliar a estabilidade intrínseca do IFA e os efeitos causados no medicamento. ${ }^{14}$

Ademais, este guia prevê a possibilidade da condução de estudos de estabilidade reduzidos, válidos apenas para medicamentos, ${ }^{14}$ além de abordar o teste de fotoestabilidade, o qual deve ser incluído no estudo de degradação forçada tanto para os IFAs quanto para os medicamentos. Diante da necessidade de maiores informações acerca destes temas, o ICH publicou guias sobre cada um deles nos anos $1995^{16}$ e $2000 .{ }^{17}$

O teste de fotoestabilidade foi melhor descrito no guia "Photostability testing of new drug substances and products", ${ }^{16} \mathrm{em}$ 1995, cuja versão em vigor é de 1996. A fotoestabilidade de novos IFAs e medicamentos deve ser avaliada para demonstrar que a exposição à luz não provoca alterações significativas nestes materiais. ${ }^{16}$ O estudo deve ser conduzido em um sistema actinométrico validado e as fontes de luz a serem utilizadas devem atender às exigências de distribuição espectral, sendo sugeridas a lâmpada D65 ou uma lâmpada fluorescente branca e outra que emita radiação no ultravioleta próximo. ${ }^{16}$ Deve ser realizado um controle de temperatura ou utilizada uma amostra controle, envolvida em folha de alumínio, de modo a protegê-la da incidência da luz, para assegurar que qualquer alteração observada não seja induzida pela temperatura. ${ }^{16}$ Os resultados obtidos deverão ser analisados para determinar se as alterações observadas 
no produto são aceitáveis e para o desenvolvimento de embalagens que o protejam da incidência da luz, quando necessário. ${ }^{16}$

Por outro lado, os estudos de estabildade reduzidos foram contemplados no guia publicado no ano 2000, intitulado "Bracketing and matrixing" ${ }^{17}$ termos referidos na legislação brasileira como agrupamento e matrização, ${ }^{11}$ respectivamente. Este tipo de estudo possibilita uma redução na quantidade total de testes a serem realizados devido à combinação de determinados fatores ou por testar apenas os extremos dos fatores. ${ }^{17}$ Consistem em um alternativa para quando há múltiplas variáveis envolvidas, como por exemplo, diferentes dosagens ou tamanhos dos recipientes de um mesmo produto. ${ }^{17}$ Entretanto, a sua utilização deve ser justificada, para tanto deve ser capaz de prever o período de reteste e o prazo de validade..$^{17} \mathrm{O}$ agrupamento consiste na realização dos testes na mesma frequência utilizada no estudo de estabilidade completo, utilizando apenas as amostras dos extremos de determinados fatores como a dosagem, por exemplo. ${ }^{17}$ Entretanto, sua aplicação, neste caso, se restringe à situação em que existam múltiplas dosagens e as formulações mantenham-se idênticas ou muito semelhantes. ${ }^{17}$ Este modelo assume que todos os níveis intermediários são representados pelos extremos testados. ${ }^{17}$ A matrização consiste na divisão das amostras em subgrupos para todos os fatores de combinação e na testagem em uma determinada frequência, sendo que nos intervalos subsequentes outro subgrupo da amostragem deverá ser testado. ${ }^{17}$ Este modelo assume que a estabilidade de cada subgrupo de amostras testado representa a estabilidade de todas as amostras em um determinado intervalo de tempo. ${ }^{17} \mathrm{~A}$ sua aplicação se estende a produtos que possuam dosagens diferentes com formulações idênticas ou similares. ${ }^{17}$

Além dos documentos abordados, foram publicados pelo $\mathrm{ICH}$ guias para a determinação de impurezas, tais como solventes residuais ${ }^{18}$ e impurezas elementares, ${ }^{19} \mathrm{em}_{\text {IFAs }}{ }^{20} \mathrm{e}$ em medicamentos. ${ }^{21}$ As impurezas farmacêuticas são substâncias químicas indesejadas, que podem ser formadas durante a síntese do fármaco e do processo de formulação, devido às possíveis interações entre os componentes da fórmula, ou durante o armazenamento. Também podem ser oriundas da embalagem que contém o medicamento. ${ }^{22} \mathrm{~A}$ presença destas substâncias, mesmo em quantidades reduzidas pode afetar a eficácia e a segurança dos produtos farmacêuticos. Os limites para impurezas são classificados em limite de notificação, no qual a impureza deverá ser reportada para a agência de vigilância sanitária; de identificação, no qual a impureza deve ser identificada por métodos apropriados; e de qualificação, em que deverá ser qualificada. ${ }^{20,21}$ A qualificação consiste no processo que estabelecerá a segurança biológica de um produto de degradação ou de um determinado perfil de impurezas especificado. ${ }^{22}$ No caso dos IFAs, o fabricante deve primeiramente elencar todas as impurezas, tanto reais quanto potenciais, que poderão surgir durante a síntese, purificação e armazenamento do IFA. ${ }^{22}$ Este resumo pode contribuir para a elucidação do perfil de degradação da substância e de possíveis produtos de degradação. ${ }^{22}$

O fabricante deve elaborar um resumo contendo todos os produtos de degradação observados durante a produção e/ou estudos de estabilidade do novo medicamento e deve resumir, também, todos os estudos conduzidos com a finalidade de detectar os produtos de degradação. ${ }^{20,21}$ Além disso, deve apresentar evidências documentadas de que os métodos analíticos utilizados foram validados e se adequam para a detecção e quantificação das impurezas analisadas. ${ }^{20,21} \mathrm{O}$ conhecimento das rotas de degradação e os estudos para o desenvolvimento do produto devem ser utilizados para caracterizar o seu perfil de degradação. ${ }^{20,21}$

Paralelamente ao ICH, a WHO publicou em 1994 o documento "Guidelines on stability testing of pharmaceutical products containing well-established drug substances in conventional dosage forms ", ${ }^{2}$ cujo objetivo é estabelecer os princípios gerais da garantia da estabilidade de medicamentos. Para tanto, define que produtos que contenham substâncias conhecidas e relativamente estáveis podem requerer um plano de estudo de estabilidade menos rigoroso do que as novas substâncias ativas e medicamentos. ${ }^{2}$ Desta forma, afirma que os estudos para medicamentos genéricos diferem daqueles destinados aos medicamentos que contém novas substâncias, uma vez que quando a patente expira, a estabilidade geralmente já está bem estabelecida, o que pode reduzir a quantidade de testes requeridos para esta substância. ${ }^{2}$ Além disso, categoriza os estudos de estabilidade em: acelerado, de longa duração, de acompanhamento e estabilidade em uso. ${ }^{2}$

Por fim, em 2017, foi publicado pela WHO o guia "Stability testing of active pharmaceutical ingredients and finished pharmaceutical products" ${ }^{23} \mathrm{O}$ documento aborda os dados de estabilidade requeridos para o registro de IFAs e medicamentos, além de recomendar os guias do ICH, de modo complementar. ${ }^{23}$ Neste documento são incluídas informações referentes ao estudo de estabilidade para os IFAs, diferentemente do guia de $1994^{2}$, destinado apenas aos produtos farmacêuticos. Além disto, acrescenta o teste de degradação forçada, incluindo o teste de fotoestabilidade, e fornece mais informações sobre a estabilidade em uso, detalhando o modo de realização deste estudo. ${ }^{23}$ Outro tipo de estudo abordado foi o do tempo de espera relacionado aos produtos a granel, o qual trata da avaliação da estabilidade dos produtos que estejam armazenados há mais de 30 dias. ${ }^{23}$ Dessa forma, pode-se dizer que houve um alinhamento das informações deste guia ${ }^{23}$ com o do ICH: "Stability testing of new drug substances and products"14, quanto à frequência, as condições requeridas para os testes de estabilidade e o restante das informações e exigências acerca do registro de IFAs e medicamentos.

Diante disto, com o intuito de facilitar a compreensão e visualização da evolução dos guias internacionais abordados previamente, um resumo das principais características destes documentos encontra-se apresentado na Tabela 1.

\section{Legislação nacional}

A primeira legislação brasileira sobre estabilidade publicada pela ANVISA foi a $\operatorname{RE~} n^{\circ} 485 / 2002,{ }^{12}$ que apresentava o guia para a realização de estudos de estabilidade. Estes estudos visam estabelecer um período de contraprova, a vida útil para medicamentos e a recomendação das condições de armazenamento. ${ }^{12} \mathrm{O}$ estudo de estabilidade, neste momento, foi classificado em apenas dois tipos: acelerado e de longa duração, cujas definições e finalidades foram condizentes com os guias internacionais. ${ }^{12}$ Era possível estabelecer um período de vida útil provisório para o medicamento com os estudos de estabilidade acelerado, o qual era aceito por um período de seis meses, ou em situações drásticas, por três meses. ${ }^{12}$ Ao final deste prazo deveria ser apresentado o estudo de longa duração para confirmar o período de vida útil do medicamento. ${ }^{12}$

Ainda no ano de 2002, a ANVISA publicou a RE $n^{\circ} 560,{ }^{24}$ que disponibilizou uma nova versão do guia para a realização de estudos de estabilidade, revogando o anterior. A nova versão não alterou significativamente a versão anteriormente publicada, sendo mantidos os tipos de estudo e suas definições, bem como os procedimentos de amostragem e as condições dos ensaios.

Entretanto, em 2004, um novo guia de estabilidade foi publicado, por meio da $\mathrm{RE} \mathrm{n}^{\mathrm{o}} 398,{ }^{11}$ o qual aborda novos conceitos, exigências e inclui outros fatores que também afetam a estabilidade, inerentes ao próprio produto, e não somente os fatores ambientais como nas versões anteriores. Subdivide os estudos de estabilidade em acelerado e de longa duração; acrescenta o estudo de estabilidade de acompanhamento e os estudos de fotoestabilidade, além de outros que sejam necessários, de acordo com as propriedades do produto 
Tabela 1. Histórico da legislação internacional sobre estabilidade de insumos e produtos farmacêuticos (adaptado a partir das referências citadas)

\begin{tabular}{|c|c|c|c|c|c|}
\hline Autor & Título & Data & $\begin{array}{c}\text { Última } \\
\text { Atualização }\end{array}$ & Código & Principais Características \\
\hline $\mathrm{ICH}$ & $\begin{array}{l}\text { Estudos de estabilidade } \\
\quad \text { para novos IFAs e } \\
\text { produtos farmacêuticos }{ }^{14}\end{array}$ & $16 / 09 / 1992$ & $06 / 02 / 2003$ & Q1A (R2) & $\begin{array}{l}\text { Define os parâmetros dos estudos de estabilidade para novos IFAs } \\
\text { e medicamentos para fins de registro. Classifica os estudos em ace- } \\
\text { lerado, intermediário, longa duração e estudo de estresse, incluindo } \\
\text { o estudo de fotoestabilidade. Prevê a possibilidade da condução de } \\
\text { estudos de estabilidade reduzidos para medicamentos. }\end{array}$ \\
\hline
\end{tabular}
estudos de estabilidade reduzidos para medicamentos.

\begin{tabular}{cccc} 
ICH $\begin{array}{c}\text { Impurezas em novos } \\
\text { IFAs }\end{array}$ & $15 / 03 / 1994$ & $25 / 10 / 2006$ & Q3A (R2) \\
& & & i \\
\hline
\end{tabular}

Classifica as impurezas, destaca os métodos analíticos e a necessidade da utilização de métodos validados e adequados para tecção e quantificação das impurezas analisadas. Estabelece limites para as impurezas, os quais se classificam em limite de identificação, de qualificação e de notificação.

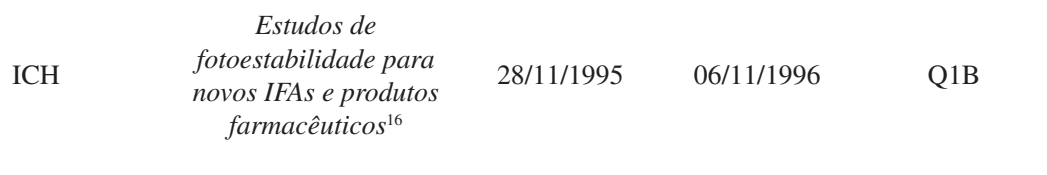

Define que o teste de fotoestabilidade deve ser conduzido em um sistema actinométrico validado e apresenta um exemplo em anexo. Fornece opções de fontes de luz: a lâmpada D65 ou uma lâmpada fluorescente branca e outra que emita no ultravioleta próximo. Estabelece que os resultados devem ser analisados para considerar a necessidade de embalagens que protejam da incidência da luz.

Complementa o guia "Impurezas em novos IFAs". Estabelece a ICH Impurezas em novos

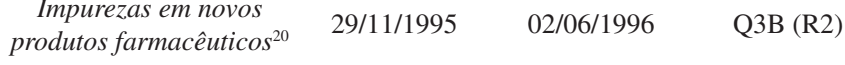
necessidade de o fabricante elucidar o perfil de degradação do produto farmacêutico. A classificação dos limites de impurezas se mantem a mesma destinada aos IFAs.

\begin{tabular}{|c|c|c|c|c|}
\hline $\mathrm{ICH}$ & Solventes residuais ${ }^{18}$ & $06 / 11 / 1996$ & $04 / 10 / 2019$ & Q3C (R6) \\
\hline
\end{tabular}

Define, classifica os solventes residuais e estabelece os limites destas substâncias. Elucida os métodos para o estabelecimento do limite de exposição.

\begin{tabular}{|c|c|c|c|c|}
\hline $\mathrm{ICH}$ & $\begin{array}{c}\text { Agrupamento e } \\
\text { matrização }^{17}\end{array}$ & $10 / 11 / 2000$ & $07 / 02 / 2002$ & Q1D \\
\hline
\end{tabular}

Destaca as aplicabilidades da modalidade de estudo de estabilidade reduzido, conceitua agrupamento e matrização com enfoque na maneira de realizar estes tipos de estudos e avaliar os resultados.

Define a avaliação dos dados de toxicidade para destacar potenciais impurezas elementares, estabelece a exposição diária permitida $\mathrm{ICH}$ Impurezas elementares $^{21} \quad 06 / 06 / 2013 \quad 22 / 03 / 2019$

Q3D (R1) para cada elemento de relevância do ponto de vista toxicológico e realiza uma abordagem baseada nos riscos para controlar as impurezas elementares em produtos farmacêuticos.

\begin{tabular}{|c|c|c|c|c|c|}
\hline WHO & $\begin{array}{l}\text { Estudos de estabilidade } \\
\text { para produtos } \\
\text { farmacêuticos que } \\
\text { contenham IFAs bem } \\
\text { estabelecidos em } \\
\text { formas farmacêuticas } \\
\text { convencionais }^{2}\end{array}$ & 1994 & 1994 & - & $\begin{array}{l}\text { Ressalta que medicamentos genéricos podem requerer estudos de } \\
\text { estabilidade menos rigorosos do que novas substâncias e produtos } \\
\text { farmacêuticos. Categoriza os estudos de estabilidade em: acelera- } \\
\text { do, de longa duração, de acompanhamento e estabilidade em uso. } \\
\text { Define que para o registro são requeridos os estudos acelerado e } \\
\text { de longa duração e destaca a possibilidade de estabelecimento de } \\
\text { prazo de validade provisório. }\end{array}$ \\
\hline WHO & $\begin{array}{c}\text { Estudos de estabilidade } \\
\text { para IFAs e produtos } \\
\text { farmacêuticos }{ }^{23}\end{array}$ & $01 / 2017$ & $01 / 2017$ & - & $\begin{array}{l}\text { Inclui os IFAs, ao contrário do guia de } 1994 \text {. Acrescenta o teste } \\
\text { de degradação forçada, incluindo o teste de fotoestabilidade e } \\
\text { fornece mais informações sobre a estabilidade em uso. Alinha as } \\
\text { informações com as do guia do ICH: "Estudos de estabilidade } \\
\text { para novos IFAs e produtos farmacêuticos", quanto à frequên- } \\
\text { cia, as condições requeridas para os testes de estabilidade e o } \\
\text { restante das informações e exigências acerca do registro de IFAs } \\
\text { e medicamentos. }\end{array}$ \\
\hline
\end{tabular}

para a comprovação da estabilidade do mesmo; e classifica o Brasil como Zona Climática IV (quente e úmida). ${ }^{11}$

O guia acrescentou informações sobre alterações pós-registro, esclareceu que tais alterações, desde que não promovam alterações na qualidade e desempenho do medicamento, viabilizam a manutenção do prazo de validade declarado no registro, desde que seja apresentada justificativa técnica acompanhada de estudo de estabilidade acelerado com resultados satisfatórios. ${ }^{11}$ Os resultados dos estudos de estabilidade devem ser apresentados por meio de relatórios, cuja finalidade é apresentar o plano de estudo, os resultados e as conclusões. ${ }^{11}$ Por fim, acrescentou a modalidade de estudo de estabilidade reduzido, classificados em agrupamento e a matrização, como na legislação internacional. ${ }^{11}$ Os conceitos, aplicações e informações acerca da realização destes estudos são similires aos estabelecidos pelos guias do ICH.
Em 2005, foi publicada pela ANVISA a RE $n^{\circ} 1,{ }^{10}$ atualizando novamente o guia de estabilidade. Entretanto, foram mantidos os três tipos de estudos de estabilidade (acelerado, de acompanhamento e de longa duração), descritos na legislação brasileira até aquele momento. Os estudos de estabilidade em uso e degradação forçada não foram abordados nesta legislação, enquanto o estudo de estabilidade pós-reconstituição ou diluição foi descrito e exigido, não recebendo, no entanto, esta nomenclatura. Além disso, esta norma abordou os produtos importados, esclarecendo que era permitido que os estudos de estabilidade fossem realizados no exterior, desde que atendessem aos requisitos da mesma. Todavia, para produtos importados em embalagem primária ou a granel, os estudos de estabilidade de acompanhamento deveriam ser realizados no Brasil. ${ }^{10}$ 
O item 2.9 da $\operatorname{RE~} n^{\circ} 1 / 2005^{10}$ exige a realização dos ensaios de identificação e quantificação dos produtos de degradação e o desenvolvimento de método analítico correspondente. Diante da necessidade de maiores orientações, a ANVISA publicou o Informe Técnico $n^{\circ} 1 / 2008,{ }^{25}$ que visava prestar esclarecimento sobre este item e determinar um prazo máximo para a adequação às exigências. $\mathrm{O}$ documento esclarece que produtos de degradação são impurezas provenientes de alterações químicas que surgem no momento da síntese do fármaco e/ou durante o armazenamento do medicamento devido a fatores como umidade, temperatura, luz, $\mathrm{pH}$ ou pelo contato com a embalagem primária ou reação com um excipiente. ${ }^{25}$ Os limites relacionados às impurezas, assim como na legislação internacional, são classificados em limite de notificação, identificação e qualificação. ${ }^{25}$ Inicialmente, deveriam ser apresentados estudos que submetessem o medicamento a condições de estresse específicas, cujo objetivo não era degradar o fármaco por completo, mas promover de $10-30 \%$ de degradação. ${ }^{25}$

Além disso, a ANVISA publicou em 2007 o Guia para a Realização de Estudos de Estabilidade para Medicamentos Dinamizados Industrializados, por meio da Instrução Normativa $n^{\circ} 4 .{ }^{26}$ Os objetivos e classificação dos estudos de estabilidade foram descritos de maneira similar aos demais guias. A determinação do prazo de validade requeria o estudo de estabilidade de longa duração, e para o registro era possível a concessão de um prazo de validade provisório de 24 meses desde que fossem atendidas as mesmas condições apresentadas na RE ${ }^{\circ} 1 / 2005 .{ }^{10}$

Diante da ausência de legislação específica destinada aos medicamentos biológicos, foi publicada a RDC $n^{\circ} 50$ de 20/2011, ${ }^{27}$ norma vigente com alterações preconizadas pela RDC n ${ }^{\circ} 25 / 2013 .{ }^{28}$ Novos conceitos foram abordados como o estudo de estabilidade cumulativa, que visa determinar o efeito da estocagem do princípio ativo, produto intermediário e produto a granel sobre a qualidade do produto biológico acabado, bem como o estudo de estresse que consiste em avaliar o impacto de curtas exposições do produto a condições fora das estabelecidas no rótulo. ${ }^{27,28}$ Diferentemente das demais classes de produtos farmacêuticos, os produtos biológicos terminados só podem ter o prazo de validade determinado pelo estudo de estabilidade de longa duração, uma vez que os estudos acelerados são insuficientes para esta finalidade. Entretanto, poderão ser aceitos estudos de longa duração parciais para a determinação do prazo de validade no momento do registro. ${ }^{27,28}$

Diante da ausência de uma norma brasileira destinada aos IFAs, foi publicada a $\operatorname{RDC~n}{ }^{\circ} 45 / 2012 .{ }^{3}$ Esta norma inclui a data de reteste do IFA, a qual deve ser determinada juntamente com o prazo de validade, por meio de um estudo de estabilidade de longa duração. ${ }^{3}$ No entanto, é possível estabelecê-los provisoriamente ao apresentar no mínimo 6 meses de estudo acelerado ou 12 meses de estudo de longa duração. O prazo de validade máximo estabelecido de maneira provisória é de 24 meses. ${ }^{3}$ Neste contexto, os testes são classificados em degradação forçada, confirmatórios e indicativos de estabilidade. O primeiro tem como finalidade avaliar a estabilidade intrínseca do IFA e o segundo visa definir as condições utilizadas na embalagem, manipulação e rotulagem do IFA. O último está relacionado com métodos analíticos quantitativos validados para a análise de amostras de estabilidade, os quais devem ser capazes de identificar, no decorrer do tempo, mudanças nas propriedades químicas, microbiológicas ou físicas de uma substância. Os testes de degradação forçada visam auxiliar na identificação de prováveis produtos de degradação, bem como na determinação do procedimento analítico que deve ser utilizado no estudo de estabilidade. Como as condições empregadas neste teste são extremas, desde que o produto de degradação não seja formado nas condições de estabilidade acelerada e de longa duração, não é necessário avaliá-lo. ${ }^{3}$
Posteriormente, em 2013, foi publicada a RDC no $58^{29}$ que estabelecia parâmetros para a notificação, identificação e qualificação de produtos de degradação em medicamentos com substâncias ativas semissintéticas e sintéticas, classificados como novos, similares e genéricos. A norma previa a elaboração do perfil de degradação do medicamento e definia que o estudo de degradação forçada deveria promover a degradação superior a 10\% e inferior à degradação completa da amostra. Os resultados desses ensaios dariam suporte para o desenvolvimento e validação do método de análise dos produtos de degradação elucidados e para análise crítica do perfil de degradação do medicamento. ${ }^{29}$

Em 2015, a ANVISA publicou uma nova regulamentação para a notificação, identificação e qualificação de produtos de degradação em medicamentos, por meio da RDC n ${ }^{\circ} 53 / 2015,{ }^{30}$ que vigora com alterações previstas pela RDC $\mathrm{n}^{\circ} 171 / 2017 .{ }^{31}$ Os conceitos, definições, parâmetros e exigências acerca do tema não foram alterados. Entretanto, houve maior detalhamento da aplicação da Resolução em relação às alterações pós-registro, sendo esclarecido que nos casos em que haja alteração de qualquer natureza relacionada à produção e análise do medicamento, a mesma deverá ser atendida. ${ }^{30,31}$

Além das normas abordadas, a ANVISA publicou outros documentos relacionados à estabilidade com o objetivo de expor o entendimento da agência com relação às melhores práticas, métodos e rotinas para cumprimento da legislação e sanar as dúvidas mais recorrentes, abrindo um espaço para a participação da sociedade. Desta forma, publicou em 2015 o Guia n 04, intitulado "Guia para obtenção do perfil de degradação, e identificação e qualificação de produtos de degradação em medicamentos". ${ }^{22}$ Este documento deve ser utilizado como referência para o cumprimento legislativo, especificamente da RDC 53/2015. ${ }^{30}$ Assim, esclarece que o perfil de degradação de interesse sanitário é gerado pela condição na qual o medicamento é exposto em sua vida útil, realizado no estudo de estabilidade de longa duração, cuja denominação é perfil de degradação "real". ${ }^{22} \mathrm{O}$ desenvolvimento de método indicativo de estabilidade para produtos de degradação requer a realização de um estudo de degradação forçada, e, este método deve ser capaz de detectar e quantificar todos os produtos de degradação relevantes do perfil de degradação "real". Portanto, para a obtenção de um perfil de degradação, deve-se utilizar o estudo de degradação forçada e, assim, desenvolver o método indicativo de estabilidade. A cromatografia líquida de alta eficiência com detector de arranjo de diodos (DAD, em inglês Diode Array Detector) é a técnica de análise recomendada. Após o desenvolvimento e validação do método utilizando o detector $\mathrm{DAD}$, pode-se utilizar o detector ultravioleta. ${ }^{22} \mathrm{O}$ estudo de degradação forçada deve gerar todos os possíveis produtos de degradação. Como as condições utilizadas são mais extremas, geralmente aparecerão mais produtos de degradação nesta situação do que nos estudos de estabilidade de longa duração. ${ }^{22} \mathrm{O}$ objetivo, então, é gerar o perfil de degradação "potencial" com a degradação forçada, no qual possivelmente mais produtos de degradação serão gerados em relação ao perfil de degradação "real" obtido com o estudo de longa duração. Dessa forma, o perfil "potencial", que é mais amplo, conterá o perfil "real" e, assim, o método indicativo de estabilidade com ele desenvolvido será capaz de identificar com exatidão os produtos de degradação em condições que simulem a realidade. ${ }^{22}$

O documento complementar "Perguntas e respostas sobre a RDC 53/2015 e o Guia 04/2015" foi publicado em $2017^{32}$ com o objetivo de esclarecer as perguntas mais frequentes recebidas pela ANVISA acerca dos documentos referidos. Os assuntos abordados são divididos em seções que esclarecem a parte conceitual sobre o perfil de degradação e estudo de degradação, exemplifica e aborda questões práticas, elucida os requisitos quanto às especificações e métodos de análise e quanto aos estudos de estabilidade, além de 
esclarecer sobre questões de registro e pós-registro dos produtos farmacêuticos.

O documento discorre sobre o motivo pelo qual a ANVISA não determinou os limites de concentração dos degradantes a serem utilizados no estudo de degradação forçada, que é a ausência de harmonização quanto aos limites de exposição (endpoints), até mesmo na literatura científica. ${ }^{32}$ Para tanto, recomenda referências que podem ser utilizadas e, assim, justificar os endpoints escolhidos para embasar o estudo. ${ }^{32}$ São abordados vários outros aspectos relevantes que contribuem para um melhor entendimento da legislação, e consequentemente, é fornecido um subsídio para que as empresas/indústrias possam se adequar aos requisitos legais quanto aos estudos de estabilidade e às questões de registro e pós-registro junto à ANVISA.

\section{$R D C n^{\circ} 318 / 2019$ (ANVISA)}

Recentemente publicada, a RDC n $318 / 2019^{9}$ estabelece os critérios para a realização de estudos de estabilidade de IFAs e medicamentos, exceto biológicos, e dá outras providências. Com ela foram revogadas as principais normas sobre estudos de estabilidade: RE $n^{\circ} 1 / 2005,{ }^{10}$ IN n $^{\circ} 4 / 2007^{26}$ e RDC n ${ }^{\circ} 45 / 2012 .{ }^{3}$ Nesta legislação são reunidas as informações e requerimentos legais, com maior detalhamento, quanto aos estudos de estabilidade para os IFAs, medicamentos novos, inovadores, genéricos, similares, dinamizados, específicos, de notificação simplificada, fitoterápicos e radiofármacos. ${ }^{9} \mathrm{~A}$ norma esclarece as peculiaridades relacionadas a cada categoria de medicamento no que diz respeito à realização dos estudos de estabilidade, diferentemente da RE ${ }^{\circ} 1 / 2005^{10}$ que apenas referia destinar-se aos produtos farmacêuticos de uma forma geral.

Além disso, aborda o estudo de estabilidade em uso, que só havia sido incluído na $\mathrm{RDC} \mathrm{n}{ }^{\mathrm{o}} 50^{27}$ referente a produtos biológicos, e destaca que os métodos indicativos de estabilidade devem ser capazes de mensurar com exatidão o teor do IFA, dos produtos de degradação e outros componentes de interesse, sem interferência. Desta forma, deixa clara a necessidade destes métodos possuírem detectabilidade (nessa revisão esse termo é entendido como a quantidade mínima da espécie química em massa que o sistema analítico consegue mensurar) ${ }^{33}$ e seletividade (capacidade de um método analítico identificar ou quantificar o analito de interesse, inequivocamente, na presença de componentes que podem estar presentes na amostra, como impurezas, diluentes e componentes da matriz $)^{34}$ adequadas.

No que diz respeito à estabilidade após a reconstituição, a RE $n^{\circ}$ $1 / 2005^{10}$ já requeria a apresentação de informações iniciais e finais que comprovassem o período de utilização pelo qual o produto mantinha a sua estabilidade após a reconstituição, mas não eram especificados os tipos de estudo de estabilidade requeridos para este fim. Neste sentido, a norma em questão aborda mais detalhadamente o estudo de estabilidade pós-reconstituição ou diluição para medicamentos e esclarece que, para esta finalidade, deve ser realizado o estudo de estabilidade de longa duração. ${ }^{9}$

Ademais, foram especificados os testes requeridos para os estudos de estabilidade dos IFAs e medicamentos. ${ }^{9}$ Para os IFAs, são necessários os testes de aspecto, teor do IFA, quantificação dos produtos de degradação individuais e totais e identificação dos produtos de degradação, quando aplicável. ${ }^{9}$ Para os medicamentos, também são requeridos os testes de aspecto, teor e quantificação dos produtos de degradação, além de dissolução ou teste de desempenho do produto (dependendo da forma farmacêutica), $\mathrm{pH}$ e quantificação de antimicrobianos e antioxidantes, quando aplicáveis. ${ }^{9}$

A fim de sintetizar e promover uma melhor visualização da evolução da legislação brasileira, um resumo das principais características destes documentos encontra-se na Tabela 2. Um aspecto importante a ser destacado é a semelhança da evolução da legislação brasileira sobre estabilidade de fármacos e produtos farmacêuticos em relação à legislação internacional, especialmente aos documentos do ICH. Diante disso, um esquema que correlaciona estas legislações é apresentado na Figura 1.

\section{EVOLUÇÃO DOS MÉTODOS ANALÍTICOS UTILIZADOS NOS ESTUUDOS DE ESTABILIDADE}

Durante o desenvolvimento de métodos indicativos de estabilidade é imprescindível a utilização de técnicas analíticas que apresentem seletividade e detectabilidade adequadas para detecção e quantificação do(s) fármaco(s) de interesse e seus produtos de degradação.

Mollica e colaboradores, em 1978, classificaram os métodos indicativos de estabilidade em eletrométricos (titulação e polarografia), extração por solvente, espectrofotométricos e cromatográficos. ${ }^{35}$ À medida que as exigências regulatórias referentes aos estudos de degradação forçada e de estabilidade de IFAs e medicamentos foi evoluindo e aumentando seu rigor, técnicas mais avançadas de separação e detecção vêm sendo cada vez mais utilizadas.

A titulação, extração por solvente e a espectrofotometria na região do ultravioleta/visível (UV/Vis) são técnicas com limitada seletividade e detectabilidade. No entanto, há relatos na literatura da utilização destas técnicas na detecção específica do fármaco de interesse em meio à matriz contendo excipientes, produtos de degradação e impurezas. ${ }^{36}$ Al-Malaq e colaboradores desenvolveram método espectrofotométrico

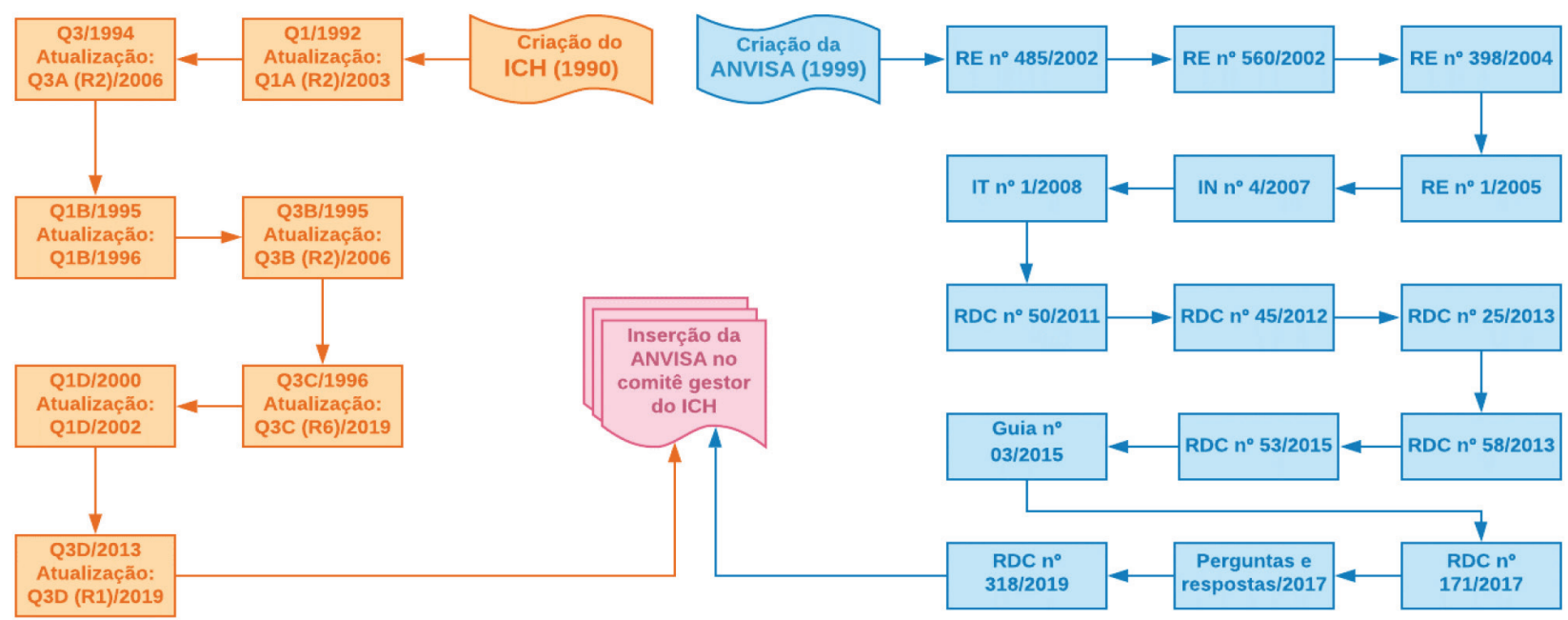

Figura 1. Evolução da legislação sobre estabilidade de fármacos e produtos farmacêuticos, publicadas pela ANVISA e ICH. 
Tabela 2. Histórico da legislação brasileira sobre estabilidade de insumos e produtos farmacêuticos

\begin{tabular}{|c|c|c|c|c|}
\hline Legislação & Data & Título & Status & Principais Características \\
\hline $\operatorname{RE~n}^{\circ} 485$ & $19 / 03 / 2002$ & $\begin{array}{l}\text { Guia para a Realização de } \\
\text { Estudos de Estabilidade }^{12}\end{array}$ & Revogada & Estudo acelerado e longa duração: Definição, condições e aplicação. \\
\hline $\operatorname{RE~n}^{\circ} 560$ & $01 / 04 / 2002$ & $\begin{array}{l}\text { Guia para a Realização de } \\
\text { Estudos de Estabilidade }^{24}\end{array}$ & Revogada & Revoga a RE N ${ }^{\circ} 485$, mas não a altera significativamente. \\
\hline $\mathrm{RE} \mathrm{n}^{\circ} 398$ & $12 / 11 / 2004$ & $\begin{array}{l}\text { Guia para a Realização de } \\
\text { Estudos de Estabilidade }^{11}\end{array}$ & Revogada & $\begin{array}{l}\text { Revoga a RE } N^{\circ} 560 \text {, mantém os estudos acelerado e de longa duração, } \\
\text { acrescenta os estudos de acompanhamento e de fotoestabilidade. Altera } \\
\text { a frequência dos testes. Introduz o conceito de zonas climáticas e os } \\
\text { modelos de estudo de estabilidade reduzidos: agrupamento e matrização. }\end{array}$ \\
\hline $\operatorname{REn}^{\circ} 1$ & $29 / 07 / 2005$ & $\begin{array}{l}\text { Guia para a Realização de } \\
\text { Estudos de Estabilidade }^{10}\end{array}$ & Revogada & $\begin{array}{l}\text { Revoga a RE N }{ }^{\circ} 398 \text {, mantém os estudos acelerado, acompanhamento e } \\
\text { longa duração. Define condições dos testes para cada forma farmacêutica. } \\
\text { Altera as condições para requerer o prazo de validade provisório e elucida } \\
\text { as exigências para produtos importados. }\end{array}$ \\
\hline IN no 4 & $11 / 04 / 2007$ & $\begin{array}{l}\text { Guia para a Realização de } \\
\text { Estudos de Estabilidade para } \\
\text { Medicamentos Dinamizados }{ }^{26}\end{array}$ & Revogada & $\begin{array}{l}\text { Os tipos de estudos, definições e condições são os mesmos requeridos } \\
\text { para os demais medicamentos. Define os testes necessários para cada } \\
\text { forma farmacêutica. }\end{array}$ \\
\hline $\mathrm{IT} \mathrm{n}^{\mathrm{o}} 1$ & $15 / 07 / 2008$ & $\begin{array}{l}\text { Esclarece o item } 2.9 \text { do anexo } \\
\text { da Resolução RE } N^{\circ} 1^{25}\end{array}$ & Vigente & $\begin{array}{l}\text { O item } 2.9 \text { preconiza a realização do ensaio de identificação e quanti- } \\
\text { ficação de produtos de degradação e método analítico correspondente } \\
\text { no estudo de estabilidade. A IT } N^{\circ} 1 \text { define as condições do teste de } \\
\text { degradação forçada, cujo objetivo é atingir de } 10 \% \text { a } 30 \% \text { de degradação. } \\
\text { Define os limites de notificação, identificação e qualificação. }\end{array}$ \\
\hline
\end{tabular}

\begin{tabular}{|c|c|c|c|c|}
\hline $\mathrm{RDC}^{\circ} 50$ & $10 / 09 / 2011$ & $\begin{array}{l}\text { Procedimentos e condições } \\
\text { de realização de estudos de } \\
\text { estabilidade para o registro } \\
\text { ou alterações pós-registro de } \\
\text { produtos biológicos }^{27}\end{array}$ & $\begin{array}{l}\text { Vigente com altera- } \\
\text { çôes previstas pela } \\
\text { RDC N } 25 / 2013\end{array}$ & $\begin{array}{l}\text { Define as condições para os estudos, exigências para o relatório de esta- } \\
\text { bilidade e requisitos para registro e alterações pós-registro. }\end{array}$ \\
\hline $\mathrm{RDC} \mathrm{n}^{\circ} 45$ & 09/08/2012 & $\begin{array}{l}\text { Dispõe sobre a realização de } \\
\text { estudos de estabilidade de } \\
\text { IFAs. }{ }^{3}\end{array}$ & Revogada & $\begin{array}{l}\text { Publica o Regulamento Técnico para os estudos de estabilidade para os } \\
\text { IFAs que abrange todas as exigências, condições, frequência de testes e } \\
\text { requisitos mínimos para o relatório de estabilidade. }\end{array}$ \\
\hline $\mathrm{RDC} \mathrm{n}^{\circ} 58$ & $20 / 12 / 2013$ & $\begin{array}{c}\text { Estabelece parâmetros para } \\
\text { a notificação, identificação e } \\
\text { qualificação de produtos de } \\
\text { degradação em medicamentos }{ }^{29}\end{array}$ & Revogada & $\begin{array}{l}\text { Definição mais detalhada da condução dos estudos de degradação (IFA, } \\
\text { placebo e medicamento) e das situações nas quais os produtos de degrada- } \\
\text { ção devem ser notificados, identificados e qualificados. Estabelece que a } \\
\text { norma entraria em vigor } 24 \text { meses após sua publicação. }\end{array}$ \\
\hline $\mathrm{RDC} \mathrm{n}^{\circ} 53$ & $04 / 12 / 2015$ & $\begin{array}{c}\text { Estabelece parâmetros para } \\
\text { a notificação, identificação e } \\
\text { qualificação de produtos de } \\
\text { degradação em medicamentos }{ }^{30}\end{array}$ & $\begin{array}{l}\text { Em vigor com alter- } \\
\text { ações previstas pela } \\
\text { RDC } N^{\circ} 171 / 2017\end{array}$ & $\begin{array}{l}\text { Muito similar à RDC } 58 \text {; a diferença consiste na definição de um } \\
\text { calendário para atendimento à norma, organizado com a divisão dos } \\
\text { medicamentos em escalões de classes terapêuticas. }\end{array}$ \\
\hline Guia n ${ }^{\circ} 04$ & $08 / 12 / 2015$ & $\begin{array}{l}\text { Guia para obtenção do perfil } \\
\text { de degradação, e identificação } \\
\text { e qualificação de produtos de } \\
\text { degradação em medicamentos }\end{array}$ & Vigente & $\begin{array}{l}\text { Detalhamento dos procedimentos a serem adotados em estudos de } \\
\text { degradação forçada e desenvolvimento de métodos indicativos de esta- } \\
\text { bilidade, além de conceitos e definições mais completas. }\end{array}$ \\
\hline $\mathrm{RDC} \mathrm{n}^{\circ} 171$ & $22 / 08 / 2017$ & $\begin{array}{l}\text { Revisa a aplicabilidade da } \\
\text { RDC 53/2015 }\end{array}$ & Vigente & $\begin{array}{l}\text { Amplia as aplicações da RDC } 53 / 2015 \text { e mantem o escalonamento de } \\
\text { classes terapêuticas para o estabelecimento das datas nas quais a norma } \\
\text { entra em vigor. }\end{array}$ \\
\hline $\begin{array}{l}\text { Perguntas e } \\
\text { respostas }\end{array}$ & 04/10/2017 & $\begin{array}{l}\text { Perguntas e respostas sobre } \\
\text { a RDC 53/2015 e o Guia } \\
4 / 2015^{32}\end{array}$ & Vigente & $\begin{array}{l}\text { Presta esclarecimentos sobre os estudos do perfil de degradação e } \\
\text { degradação forçada, situações em que a RDC } 53 / 2015 \text { não se aplica e } \\
\text { como atender à essa norma para fins de registro e alterações pós-registro. }\end{array}$ \\
\hline $\mathrm{RDC} \mathrm{n}^{\circ} 318$ & $06 / 11 / 2019$ & $\begin{array}{l}\text { Estabelece os critérios para } \\
\text { a realização de estudos de } \\
\text { estabilidade de IFAs e medica- } \\
\text { mentos, exceto biológicos, e dá } \\
\quad \text { outras providências }^{9}\end{array}$ & Vigente & $\begin{array}{l}\text { Reúne informações e requerimentos legais para estudos de estabilidade } \\
\text { de IFAs, medicamentos e medicamentos dinamizados. Inclui novos con- } \\
\text { ceitos como estabilidade em uso, aborda mais detalhadamente o estudo } \\
\text { de estabilidade pós-reconstituição, especifica quais testes são requeridos } \\
\text { para os estudos de estabilidade. }\end{array}$ \\
\hline
\end{tabular}

para a determinação de fenoterol em formulações farmacêuticas (comprimido e aerossol para inalação oral), com detecção em $436 \mathrm{~nm}$ (após reação do fármaco com benzocaína, ácido sulfúrico, nitrito de sódio e trietilamina), que foi considerado seletivo em relação ao ipratrópio (fármaco presente em formulações de dose fixa combinada com o fenoterol), excipientes comuns (talco, lactose e estearato de magnésio) e produtos provenientes da degradação alcalina do fármaco. ${ }^{37}$

A utilização da espectrofotometria derivativa promoveu melhora na seletividade durante a análise de misturas e, por isso, encontram-se descritos alguns métodos para avaliação da estabilidade de fármacos utilizando essa técnica. Um exemplo é o estudo realizado por Archontaki, no qual foi investigada a cinética de degradação da indometacina em meio alcalino, utilizando-se espectrofotometria derivativa de quarta ordem. O uso dessa técnica possibilitou resolução adequada entre os sinais do analito e do produto de degradação formado. ${ }^{38}$

Dentre as inúmeras técnicas que podem ser utilizadas para análise 
de amostras de fármacos degradados, a mais utilizada é a cromatografia, que inclui a cromatografia em camada delgada (CCD ou TLC, do inglês Thin-layer chromatography), cromatografia em camada delgada de alta eficiência (CCDAE ou HPTLC, do inglês High-performance thin-layer chromatography), cromatografia líquida de alta e ultra eficiência (CLAE ou HPLC, do inglês High performance liquid chromatography e CLUE ou UHPLC do inglês Ultra high performance liquid chromatography) e cromatografia gasosa (CG). ${ }^{39}$ Devido à possibilidade de separar múltiplos componentes durante a análise das amostras, à maior precisão e detectabilidade, os métodos cromatográficos têm precedência sobre os métodos convencionais de análise, principalmente quando se trata de amostras provenientes de estudos de estabilidade..$^{36,40}$

A CCD constitui uma das técnicas analíticas mais antigas e que foi e continua sendo amplamente utilizada na indústria farmacêutica. ${ }^{39}$ Suas grandes vantagens consistem na simplicidade e na rapidez da análise. Encontram-se descritos na literatura diversos métodos por CCD para avaliação da estabilidade de produtos farmacêuticos. Esta técnica é muito utilizada durante a etapa inicial dos estudos de degradação forçada, na identificação dos produtos de degradação formados por meio da correspondência com padrões de referência e também para o isolamento dos mesmos por meio da CCD preparativa. ${ }^{36}$ Há vários trabalhos nos quais são realizadas análises por CCD associada principalmente à densitometria, para a quantificação do fármaco na presença dos produtos de degradação. ${ }^{41-43}$ Treiber, em 1986, realizou um estudo de estabilidade acelerado para diversos fármacos sensíveis à oxidação e utilizou a CCD associada à densitometria para a construção de gráficos de cinética de degradação. ${ }^{44}$ Um outro trabalho foi desenvolvido por Schlemmer e Kammerl em 1973, no qual foi utilizada a CCD quantitativa para avaliação da estabilidade de cloridrato de tiamina em um produto líquido e de cloridrato de noscapina em solução aquosa, nos quais a mancha referente ao fármaco foi separada dos prováveis produtos de degradação e quantificada por espectroscopia de reflectância. ${ }^{45}$ Além dos estudos reportados na literatura, encontram-se descritos nos diversos compêndios oficiais farmacêuticos, diferentes métodos utilizando CCD para a realização dos testes de substâncias relacionadas e determinação de impurezas orgânicas em fármacos e medicamentos. ${ }^{1,46-48}$

A utilização de placas cromatográficas constituídas por fase estacionária de menor tamanho de partícula, técnica conhecida como CCDAE, favoreceu a resolução entre as manchas e, consequentemente, promoveu melhor separação entre o fármaco e os produtos de degradação. Dessa forma, encontram-se descritos na literatura vários métodos indicativos de estabilidade utilizando essa técnica para avaliação de fármacos e preparações farmacêuticas. ${ }^{49-54} \mathrm{Um}$ exemplo de utilização da CCDAE é o estudo realizado por Dixit e colaboradores, no qual foi desenvolvido e validado um método para quantificação simultânea, por densitometria, de sinvastatina e ezetimibe na presença dos produtos provenientes da degradação em meios ácido, tampão fosfato $\mathrm{pH}$ 6,8, oxidativo, calor seco e umidade..$^{55}$

Devido à sua capacidade de alta resolução, seletividade e detectabilidade, a CLAE é a técnica mais utilizada no desenvolvimento de métodos indicativos de estabilidade. ${ }^{36}$ A CLAE foi desenvolvida na década de 1960, aprimorada nos anos 70 e começou a ser amplamente utilizada, inclusive na avaliação da estabilidade de produtos farmacêuticos, a partir da década de $1980 .{ }^{56}$ São inúmeros os métodos indicativos de estabilidade descritos na literatura utilizando CLAE para obter separação adequada entre o fármaco e os produtos de degradação.

Dentre os diferentes tipos de detectores que podem ser acoplados à CLAE, os espectrofotométricos de absorção no ultravioleta (UV) são os mais frequentemente utilizados para análises farmacêuticas, seja do tipo comprimento de onda variável ou DAD. ${ }^{39,40}$ Quando são utilizados detectores de comprimento de onda variável, a recomendação é que o comprimento de onda de detecção do método indicativo de estabilidade seja relativamente baixo, ou seja, o mais próximo possível de $200 \mathrm{~nm}$, para que assim aumente a probabilidade de que todos os produtos de degradação formados possam ser detectados, já que esta é uma região do espectro eletromagnético menos seletiva. ${ }^{39}$ Diego e colaboradores submeteram o maleato de enalapril IFA e diferentes formulações de comprimidos contendo esse fármaco a várias condições de estresse (ácida, neutra, alcalina, oxidação, aquecimento e fotodegradação), ao armazenamento sob condições de estudo de estabilidade acelerado e, a partir das amostras degradadas, desenvolveram método indicativo de estabilidade por CLAE-UV com detecção em $215 \mathrm{~nm}^{57}$

A utilização de um detector DAD promove aumento significativo das informações que são obtidas durante a análise cromatográfica. Ao se utilizar esse tipo de detector é possível extrair cromatogramas em diversos comprimentos de onda a partir de uma única corrida cromatográfica, obter os espectros de varredura na região do UV dos picos cromatográficos individuais e, além disso, determinar a homogeneidade espectral de cada pico cromatográfico, sendo essa uma indicação da ausência de coeluições (teste de pureza de pico). ${ }^{39}$ Diante dessas vantagens e, em prol do cumprimento das exigências legislativas, a utilização da CLAE com detector do tipo DAD vem se tornando cada vez mais imprescindível. No trabalho científico realizado por Panditrao e colaboradores, no qual é descrito um método indicativo de estabilidade para determinação de dicloridrato de pramipexol em IFA e comprimidos na presença dos produtos de degradação formados em meio ácido, alcalino e oxidativo, o teste de pureza de pico foi utilizado para comprovar a seletividade do método. ${ }^{58}$ Um outro estudo no qual a CLAE-DAD foi a técnica de escolha para determinar os dados de pureza de pico e garantir a seletividade do método indicativo de estabilidade desenvolvido para análise do cloridrato de donepezila e seus produtos de degradação foi descrito por Ruela e colaboradores. ${ }^{59}$ Cione e colaboradores utilizaram amostras provenientes da degradação forçada (hidrólise ácida e alcalina, oxidação, luz e calor) da ampicilina benzatina e da ampicilina sódica para desenvolver método indicativo de estabilidade por CLAE-DAD, no qual os parâmetros de resolução, simetria e pureza de pico foram monitorados durante a otimização do método cromatográfico. ${ }^{60}$

Devido ao seu amplo campo de aplicação, sensibilidade e faixa de linearidade, a detecção por UV é a mais comumente aplicada no desenvolvimento de métodos indicativos de estabilidade. Entretanto, dentre as limitações referentes à utilização desse tipo de detector, está a necessidade do analito apresentar grupo cromóforo para sua detecção, o que pode prejudicar a determinação de fármacos, produtos de degradação e impurezas que não possuem grupamentos químicos que absorvam na região UV do espectro eletromagnético. ${ }^{61}$ Outra limitação dos detectores UV durante a análise de produtos de degradação e impurezas é o fato desses analitos poderem apresentar o mesmo grupo cromóforo que o fármaco. Assim, se ocorrer uma coeluição dos mesmos, a seletividade do método analítico pode ser comprometida. Como alternativa para essas limitações, outros detectores, como espectrômetro de massas, detector por espalhamento de luz evaporativo (ELSD, em inglês Evaporative Light Scattering Detector) e detector de aerossol carregado (CAD, em inglês Charged Aerosol Detector), podem ser acoplados à CLAE e utilizados no desenvolvimento de métodos indicativos de estabilidade. ${ }^{61,62}$

A detecção por fluorescência (FLU) não é muito recomendada ao se desenvolver um método indicativo de estabilidade, uma vez que, apesar do fármaco poder fluorescer, não é possível garantir que os produtos de degradação também apresentarão o mesmo comportamento químico. ${ }^{39}$ Todavia, encontram-se na literatura alguns estudos que utilizaram CLAE acoplado a detector de fluorescência (CLAE-FLU) para avaliação da estabilidade de fármacos e produtos farmacêuticos. 
Kamal e colaboradores descrevem um método por CLAE-FLU capaz de determinar daclatasvir na presença dos produtos de degradação formados em meio ácido e alcalino. Esses pesquisadores relatam ainda que os resultados de determinação do teor de daclatasvir em comprimidos obtidos a partir do método fluorimétrico desenvolvido são concordantes com os resultados obtidos utilizando-se um método com detecção na região do UV..$^{63}$

A detecção por espectrometria de massas (EM), no caso de métodos indicativos de estabilidade, contribui para a detectabilidade e seletividade do método analítico, além de ser muito útil para a elucidação estrutural dos produtos de degradação e seu uso é recomendado ainda para análise de fármacos e produtos de degradação que não apresentam grupos cromóforos. ${ }^{39}$ A separação conseguida por meio de um sistema cromatográfico adicionado às informações das razões massa/carga dos íons disponibilizadas pelo espectrômetro de massas permite propor as estruturas químicas dos produtos de degradação desconhecidos sem a necessidade de isolamento dos mesmos. ${ }^{64}$ Estão presentes na literatura trabalhos utilizando diferentes tipos de analisadores de massas, dentre eles os quadrupolos, armadilha de íons (IT, do inglês Ion trap) e aqueles baseados no tempo de voo (TOF, do inglês Time-of-fight).

Apesar de serem considerados de baixa resolução, encontram-se descritos diversos trabalhos nos quais foram utilizados espectrômetros de massas do tipo quadrupolo para a elucidação estrutural de produtos de degradação. Um exemplo dessa aplicação é o estudo realizado por Bernardi e colaboradores, que acoplaram a CLAE a um espectrômetro de massas do tipo quadrupolo para realizar a identificação dos dois produtos provenientes da degradação térmica do antitrombótico etexilato de dabigatrana. ${ }^{65}$

$\mathrm{O}$ analisador de massas do tipo armadilha de íons permite uma pré-concentração do(s) íon(s) de interesse, aumentando assim a detectabilidade do método analítico. Já os analisadores de massas do tipo TOF não lineares com refletores de íons, são considerados de alta resolução e, por isso, a sua aplicação na elucidação estrutural dos produtos de degradação é recomendada.

Analisadores de massas sequenciais (híbridos) proporcionam maior facilidade e confiabilidade na proposta das estruturas químicas dos produtos de degradação, uma vez que, além de fornecerem a razão massa/carga do(s) íon(s) precursor(es), podem ser obtidas também as razões massa/carga dos respectivos íons produtos. ${ }^{62}$ Raju e colaboradores desenvolveram e validaram método utilizando CLAE acoplada a um espectrômetro de massas híbrido do tipo quadrupolo-tempo de voo para a caracterização de 16 produtos provenientes da degradação hidrolítica (ácida, neutra, alcalina) e oxidativa da prulifloxacina. ${ }^{66}$ Zhou e colaboradores utilizaram as informações provenientes de dois métodos, um deles por CLAE acoplada a espectrômetro de massas do tipo triplo quadrupolo-armadilha de íons linear e outro método por CLAE acoplado a espectrômetro de massas por armadilha de íons-tempo de voo para realizarem a identificação de sete produtos provenientes da degradação do antiepilético lacosamida. ${ }^{67}$

Além disso, o acoplamento de mais de um tipo de detector em série também é utilizado para se obter diferentes informações a respeito dos produtos de degradação formados durante o desenvolvimento do método indicativo de estabilidade. ${ }^{39}$ Um exemplo é o acoplamento de detectores DAD a um espectrômetro de massas, que contribui para o processo de elucidação estrutural dos produtos de degradação. Os produtos de degradação provenientes do bromidrato de citalopram foram identificados por Sharma e colaboradores por meio das informações provenientes do método por CLAE-DAD e de um método por CLAE-MS ${ }^{68}$ Reis e colaboradores utilizaram cromatógrafo a líquido de alta eficiência com detector DAD acoplado a espectrômetro de massas sequencial para propor a estrutura química e mecanismo de formação de três produtos provenientes da degradação da nevirapina. ${ }^{69}$
Coelho e colaboradores também propuseram as estruturas químicas dos produtos de degradação advindos da cloroquina na presença de peróxido de hidrogênio utilizando detector DAD e espectrômetro de massas sequencial. ${ }^{70}$

Os detectores ELSD e CAD também são alternativas na detecção de analitos que não absorvem na região do UV, uma vez que não requerem que os analitos apresentem grupos funcionais específicos ou cromóforos. ${ }^{71}$ Por meio de métodos CLAE-ELSD é possível analisar qualquer analito que seja menos volátil que a fase móvel. ${ }^{71}$ Assim como muitos outros aminoglicosídeos, a espectinomicina não possui um grupo cromóforo, necessário à sua detecção no UV; por isso, são encontrados na literatura métodos que utilizam derivatização para a sua determinação. Entretanto, Zhou e colaboradores desenvolveram um método por CLAE-ELSD para determinação direta de cloridrato de espectinomicina e sete substâncias relacionadas sem a etapa de derivatização. ${ }^{72}$ Em relação ao princípio de funcionamento do $\mathrm{CAD}$, o mesmo é semelhante ao ELSD, havendo a conversão do analito em partículas finas. No entanto, em vez de usar a dispersão da luz, seu funcionamento baseia-se na aplicação de uma carga às partículas, por meio de uma descarga corona, e posterior medição da quantidade de partículas carregadas por meio de um eletrômetro. ${ }^{39}$ Devido à estrutura química da netilmicina e suas substâncias relacionadas, as mesmas apresentam baixa absorção na região do UV, o que compromete a detectabilidade dos métodos que utilizam esse tipo de detector. Para contornar esse problema, Joseph e colaboradores utilizaram CLAECAD para desenvolver um método indicativo de estabilidade para netilmicina. ${ }^{73}$

Um ponto que deve ser ressaltado, é a necessidade de quantificar os produtos de degradação formados durante o estudo de estabilidade. Quando se trata de produtos de degradação caracterizados e disponíveis isoladamente, a quantificação pode ser realizada utilizando-se o respectivo padrão de referência. Por outro lado, quando se trata de produtos de degradação não caracterizados e/ou não disponíveis para utilização na forma pura, a determinação de um fator de resposta relativo faz-se necessária para a análise quantitativa. Nesses casos, o fator de resposta do fármaco é utilizado como referência para a quantificação dos produtos de degradação desconhecidos. ${ }^{62,74}$ Entretanto, essa prática pode levar a erros de quantificação, principalmente quando se utiliza detector UV, uma vez que os produtos de degradação e o fármaco podem possuir diferentes valores de absortividade molar, fazendo com que apresentem fatores de resposta distintos. ${ }^{39}$ Apesar da utilização de baixos valores de comprimentos de onda $(205 \mathrm{~nm}$ a $210 \mathrm{~nm}$ ) aumentar a aplicabilidade da detecção UV e minimizar as diferenças nos fatores de resposta, o mais recomendado é que um detector universal, cuja resposta independe da estrutura química do analito, seja utilizado para fornecer uma relação confiável entre a magnitude da resposta e a quantidade da substância presente na amostra. ${ }^{39,74}$

Sun e colaboradores realizaram um estudo no qual os fatores de resposta relativos de nove impurezas relacionadas ao paclitaxel obtidos por CLAE-CAD foram comparados com os obtidos por CLAE-UV. Como o pico de resposta utilizando o detector CAD é independente da estrutura do analito, os fatores de resposta relativos obtidos quando empregado CLAE-CAD foram praticamente constantes para as nove impurezas analisadas e paclitaxel, com um desvio padrão relativo (DPR) da inclinação das diferentes curvas de calibração de $5,6 \%$. Por outro lado, quando utilizado o método por CLAE-UV, as respostas obtidas diferiram significativamente de um analito para outro, com fator de resposta relativo individuais variando entre 0,5 e 1,0 (DPR de 25\%). Este estudo demonstrou que erros significativos na quantificação podem ocorrer quando o fator de resposta UV de substâncias desconhecidas é assumido como um e que, a utilização de CLAE-CAD é uma forma rápida, conveniente 
e precisa para a determinação dos fatores de resposta relativos de impurezas desconhecidas. ${ }^{61,74}$

Apesar da CLAE ser considerada a técnica analítica mais desenvolvida, difundida e empregada em laboratórios analíticos de indústrias farmacêuticas e químicas, ${ }^{75}$ cada vez mais existe a demanda por métodos de análise mais rápidos, com elevada eficiência de separação e que necessitem de menor consumo de solventes orgânicos. Nesse contexto, destaca-se a utilização da CLUE. ${ }^{76}$ Um exemplo da utilização dessa técnica é o estudo descrito por Krishnaiah e colaboradores, que submeteram a valsartana a condições de degradação forçada em meios oxidativo, ácido, alcalino, neutro, térmico, fotolítico e desenvolveram método indicativo de estabilidade por CLUE-DAD de nove minutos de tempo de corrida, seletivo à valsartana na presença de sete impurezas farmacopeicas e aos produtos de degradação formados. ${ }^{77}$ Kumar e colaboradores também utilizaram a CLUE-DAD para obter método indicativo de estabilidade com dez minutos de corrida para determinação de nizatidina na presença dos conservantes metilparabeno e propilparabeno e dos produtos de degradação formados após a realização dos testes de estresse. ${ }^{78}$

No caso de amostras voláteis, a CG com detecção por ionização de chama (FID, do inglês Flame ionization detector) ou por espectrometria de massas é a técnica de escolha, como foi descrito por Jamrógiewicz e Wielgomas, que estudaram a formação de produtos voláteis a partir da fotodegradação da ranitidina em estado sólido por CG acoplada a espectrometria de massas. ${ }^{79} \mathrm{~A}$ CG pode também ser utilizada como técnica de análise complementar à cromatografia líquida, no caso de suspeita de produtos de degradação voláteis. Encontram-se também na literatura artigos nos quais são relatados métodos utilizando CG para quantificar o fármaco e suas substâncias relacionadas, como exemplificado pelo estudo descrito por Belal e colaboradores, que desenvolveram método por CG acoplada a espectrometria de massas para a determinação simultânea de dicloridrato de trimetazidina e duas substâncias relacionadas. ${ }^{80}$

Os estudos descritos são apenas alguns dentre inúmeros outros encontrados na literatura, utilizados para exemplificar a aplicação das diferentes técnicas analíticas durante a avaliação da estabilidade de fármacos e formulações farmacêuticas. Um resumo da evolução das técnicas analíticas descritas está apresentado na Figura 2.

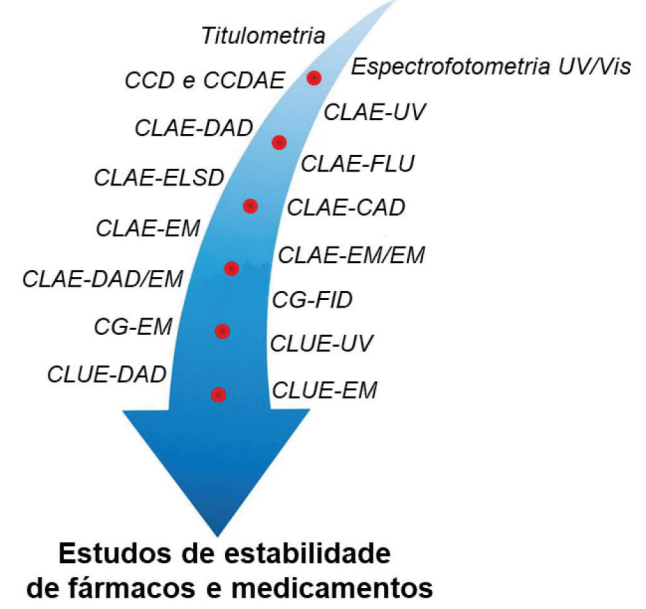

Figura 2. Técnicas analíticas utilizadas em estudos de estabilidade de fármacos e medicamentos.

\section{TÉCNICAS DE CARACTERIZAÇÃO EMPREGADAS NA AVALIAÇÃO DA ESTABILIDADE}

A utilização combinada de técnicas analíticas e de caracterização, sobretudo no estado sólido, tem sido cada vez mais demandada na avaliação da estabilidade de fármacos e produtos farmacêuticos. Vale lembrar que a maioria das formas farmacêuticas atualmente disponíves são os sólidos de uso oral (comprimidos, cápsulas, etc), ${ }^{81}$ o que reforça a necessidade de empregar essas técnicas no estudo de sólidos farmacêuticos. ${ }^{82}$ Dentre as técnicas mais utilizadas destacam-se a difração de raios X (DRX), ${ }^{83}$ as técnicas termoanalíticas de termogravimetria (TG), calorimetria exploratória diferencial (DSC, do inglês differential scanning calorimeter) e termomicroscopia ótica (TOA, do inglês termo-optical analysis) ${ }^{84}$ a espectroscopia vibracional na região do infravermelho (IV) e de espalhamento Raman, ${ }^{85}$ a ressonância magnética nuclear $(\mathrm{RMN}),{ }^{86}$ as técnicas microscópicas (microscopia eletrônica de varredura e no infravermelho $)^{87}$ e a CLAE. ${ }^{88}$ A seguir será apresentado o princípio básico dessas técnicas bem como trabalhos que ilustram a aplicação delas em estudos de estabilidade de IFAs e medicamentos.

A DRX é uma poderosa técnica de caracterização no estado sólido com ínúmeras aplicações na área de farmacêutica, inclusive em estudos de estabilidade. ${ }^{89-91} \mathrm{~A}$ técnica se baseia no espalhamento dos raios X por materias cristalinos, cuja principal característica é o ordenamento a longo alcance dos átomos e moléculas. Quando um feixe de raios $\mathrm{X}$ incide sobre um cristal que é constituído de infinitos e sucessivos planos atômicos, este interage com a densidade eletrônica, sendo difratado em certas direções e produzindo um padrão único e próprio do cristal, denominado padrão de difração. A simetria desse padrão contém informação acerca do arranjo interno das moléculas no cristal, enquanto que as intensidades das reflexões (feixes difratados) fornecem informação sobre a constituição química das moléculas. ${ }^{92}$ No caso de materias amorfos, ou seja, aqueles que não possuem ordenamento a longo alcance, os raios $\mathrm{X}$ não são espalhados de forma eficiente, não sendo possível obter um padrão de difração. Dessa forma, a DRX é a técnica mais indicada e tem sido amplamente utilizada para monitorar se, durante o período de armazenamento, ocorre perda de cristalidade dos produtos farmacêuticos ou recristalização de compostos que deveriam estar na forma amorfa. ${ }^{93-95}$

Rumondor e colaboradores investigaram a cinética de recristalização de dispersões amorfas contendo o fármaco felodipina. Os autores alteraram a umidade relativa e o tipo de polímero empregado nas preparações e demostraram, por DRX, que a estabilidade das dispersões das amostras preparadas é altamente dependente da umidade relativa e do tipo de polímero. ${ }^{96}$ Outro interessante trabalho publicado recentemente mostrou o efeito de diferentes polímeros na estabilidade física de dispersões sólidas amorfas de resveratrol. Neste trabalho, a cristalinidade do fármaco foi avaliada por DRX e foi possível selecionar polímeros que inibiram efetivamente a cristalização do resveratrol de maneira a mantê-lo na forma amorfa nas etapas de processamento e armazenamento, garantindo a estabilidade da formulação. ${ }^{97}$

As técnicas termoanalíticas são aquelas nas quais as propriedades físicas e químicas dos compostos são determinadas em função de uma variação programada de temperatura que é aplicada ao sistema, permitindo inferir sobre o comportamento térmico do material. ${ }^{98}$ Os principais eventos observados durante as análises térmicas são: fusão, decomposição, dessolvatação, desidratação, transições de fase e cristalização. A análise por DSC quantifica a energia absorvida ou liberada por uma amostra, comparado a um material de referência, quando esta é aquecida ou resfriada. ${ }^{99}$ As análises de TG mensuram a perda de massa em função da temperatura, sendo importante na determinação da estabilidade térmica de uma amostra. ${ }^{100}$ De forma a complementar, os experimentos de TOA permitem o acompanhamento, em tempo real, das transformações que acontecem na amostra, quando varia-se a temperatura, usando uma placa de aquecimento acoplada a um microscópio ótico contendo uma câmera de vídeo. ${ }^{101}$ Em geral, é sempre desejável que os resultados de DSC e TG e as 
imagens de TOA sejam correlacionados, de forma a tornar a interpretação dos eventos térmicos inequívoca.

Recentemente, vários relatos na literatura demostraram a grande aplicabilidade das análises térmicas nos estudos de estabilidade de produtos farmacêuticos, principalmente em estudos envolvendo a interação fármaco-excipientes. ${ }^{102-104}$ Giovanna e colaboradores investigaram, usando DSC, a compatibilidade entre o fármaco haloperidol e três excipientes (polivinilpirrolidona, estearato de magnésio e lactose monohidratada) em misturas binárias e ternárias. Os autores mostraram que há forte interação entre o fármaco e a polivinilpirrolidona, fato comprovado por alterações no evento de fusão das curvas de DSC. ${ }^{104}$ Em outro trabalho semelhante, Harding e colaboradores verificaram a compatibilidade de misturas físicas entre o ácido acetilsalicílico e o estearato de magnésio usando a técnica de TOA. As imagens de TOA mostraram que as partículas de ácido acetilsalicílico ficaram envolvidas por finas partículas de estearato de magnésio e uma camada líquida foi formada em torno das partículas do fármaco com o aumento da temperatura. Os autores concluíram que a redução da temperatura de fusão da mistura física de fármaco-excipiente evidencia a interação entre ambos. ${ }^{105}$

A espectroscopia vibracional é amplamente utilizada na caracterização de compostos farmacêuticos. Os espectros de absorção na região do infravermelho (IV) e espalhamento Raman fornecem importantes informações sobre os modos vibracionais das moléculas. ${ }^{106}$ Enquanto a absorção na região do IV depende da variação do momento de dipolo da molécula, o espalhamento Raman depende da polarizabilidade. Como consequência, as informações fornecidas pelos espectros IV e Raman são complementares. As bandas que aparecem em ambos os espectros são atribuídas a grupos funcionais e à conformação das moléculas, sendo, portanto, úteis na identificação e ao mesmo tempo sensíveis a alterações moleculares, ainda que sutis. ${ }^{85} \mathrm{Na}$ literatura, inúmeros trabalhos envolvendo não só IFAs como também medicamentos utilizaram espectroscopia vibracional para a avaliação da estabilidade. ${ }^{107-109}$ Saerens e colaboradores mostraram que o alargamento de bandas nos espectros Raman estava relacionado com o processo de amorfização do IFA, ou seja, uma transição de fase que compromete a estabilidade. ${ }^{110}$ Uma vez que a espectroscopia no IV e de espalhamento Raman permitem estudar interações intermoleculares, Andrews e colaboradores demostraram possíveis interações entre o excipiente polivinilpirrolidona e o fármaco antineoplásico bicalutamida, com base em deslocamentos de bandas nos espectros. ${ }^{111}$ Devido à elevada sensibilidade à água, a espectroscopia no IV pode ainda ser usada para a estimativa do conteúdo de água em produtos farmacêuticos, conforme demonstrou Rantanen e colaboradores. ${ }^{12}$

A RMN investiga ambientes atômicos com base nas diferentes frequências de ressonância exibidas por núcleos - cujo spin seja diferente de zero - quando expostos a um forte campo magnético. ${ }^{113}$ Diferentes núcleos podem ser observados nos experimentos RMN, mas os de átomos de hidrogênio $\left({ }^{1} \mathrm{H}\right)$ e carbono $\left({ }^{13} \mathrm{C}\right)$ são os mais frequentemente estudados. A RMN convencional, cujos experimentos são realizados em soluções contendo a amostra solubilizada em um solvente deuterado, é comumente usada para elucidação de estruturas. ${ }^{113}$ Por outro lado, análises por RMN no estado sólido são extremamente úteis para caracterizar sólidos farmacêuticos, sendo inclusive utilizada como técnica complementar em estudos de estabilidade, conforme demonstrado em alguns trabalhos recentemente publicados. ${ }^{114-116}$ Neste caso, os núcleos mais comumente analisados são: ${ }^{13} \mathrm{C},{ }^{31} \mathrm{P},{ }^{15} \mathrm{~N},{ }^{25} \mathrm{Mg}$ e ${ }^{23} \mathrm{Na}$. Em um trabalho publicado por Aso e colaboradores, no qual foram investigadas preparações amorfas entre os fármacos nifedipina e fenobarbital, verificou-se que a formação de ligações de hidrogênio reduziu a mobilidade molecular, aumentando assim a estabilidade dos sistemas amorfos preparados. ${ }^{117}$ Schachter e colaboradores estudaram as interações intermoleculares em uma dispersão sólida de cetoprofeno e óxido de polietileno, revelando que a formação de ligações de hidrogênio entre o fármaco e o excipiente aumenta a miscibilidade. ${ }^{118} \mathrm{Em}$ ambos os trabalhos mencionados, a mobilidade molecular foi determinada por RMN no estado sólido. Além disso, existem inúmeros trabalhos na literatura demostrando o uso do RMN de forma quantitativa para o estabelecimento de substâncias químicas de referência ${ }^{119}$ e em estudos de estabilidade, ${ }^{120}$ sem contar àqueles em que o RMN atua como técnica de detecção, principalmente quando acoplado à CLAE (CLAE-RMN). ${ }^{121}$

Os trabalhos mencionados acima, que utilizaram diferentes técnicas de caracterização no estado sólido, evidenciam o crescente uso das mesmas em estudos de estabilidade de fármacos e produtos farmacêuticos em geral, o que torna claro não só a necessidade de implementação dessas técnicas nas rotinas analíticas como também a sua inserção nos guias e legislações relacionados à estabilidade.

Ademais, nas últimas décadas, outros segmentos relacionados direta ou indiretamente ao ramo farmacêutico também deram contribuições notórias para a melhoria da estabilidade não só dos fármacos como também das formulações farmacêuticas. Como exemplos, merece destaque a engenharia de cristais, que tem se mostrado muito eficiente no melhoramento da estabilidade de IFAs, sobretudo por meio do desenho de novas formas sólidas multicomponentes ${ }^{122-125} \mathrm{e}$ os sistemas poliméricos nanoestruturados, que tem permitido endereçar, por diferentes vias de administração, fármacos extremamente instáveis, aos seus respectivos sítios de ação. ${ }^{126-128}$

\section{ANÁLISE CRÍTICA}

A legislação brasileira tem buscado um maior alinhamento à legislação internacional, especialmente em relação aos guias do ICH e da WHO, sendo possível notar que os documentos produzidos por estas agências serviram de base para a elaboração das normas brasileiras. As principais diferenças encontradas se referem às peculiaridades do clima de cada região. Entretanto, a legislação brasileira apresenta uma grande quantidade de documentos publicados, o que promove uma fragmentação do assunto, dificultando o entendimento pleno daqueles que visam realizar os estudos de estabilidade e obter o registro do seu produto junto à ANVISA.

A RE $n^{\circ} 1 / 2005$ exigia a identificação e a quantificação dos produtos de degradação com a utilização de método adequado. Entretanto, não haviam maiores explicações sobre como atender a esta exigência, o que gerou dúvida naqueles que deveriam atender à legislação. Apenas em 2008, a ANVISA publicou o Informe Técnico $n^{\circ} 1$ que prestou esclarecimentos sobre tal exigência, introduzindo a necessidade da realização de estudos que submetessem o medicamento a condições de estresse, o que em legislações posteriores ganhou a denominação de estudo de degradação forçada.

O Guia para Estudos de Estabilidade de IFAs foi publicado tardiamente, em 2012, e, anteriormente à sua publicação, não haviam exigências específicas acerca da comprovação da estabilidade de IFAs. Tais exigências são extremamente importantes, já que a formulação do medicamento deve ser desenvolvida levando em consideração os aspectos de estabilidade do fármaco que será utilizado, e que, especialmente para as situações em que as petições de registro abrangem novos fármacos ainda não existem informações robustas acerca das propriedades desta nova molécula. A RDC $\mathrm{n}^{\circ} 318$ reuniu os estudos de estabilidade de IFAs e medicamentos no mesmo documento, o que compila as informações e facilita a busca e compreensão sobre $\mathrm{o}$ assunto.

Fato que merece destaque é que não existem normas de estabilidade direcionadas especificamente aos excipientes farmacêuticos no âmbito internacional, tampouco no nacional. Considerando que a grande maioria dos medicamentos contém excipientes em sua formulação, 
é relevante direcionar a atenção também a estes constituintes, uma vez que muitas das instabilidades de formulações ocorrem devido à presença destes componentes, seja por incompatibilidade com o IFA ou devido às impurezas reativas presentes nos excipientes. Além disto, destaca-se a ausência de informações e de exigências de estudos que elucidem o comportamento dos excipientes frente às condições ambientais e com o decorrer do tempo.

Uma dificuldade que transcende as questões normativas é a ausência de harmonização quanto às condições e aos endpoints para a realização dos estudos de degradação forçada. Desta forma, não existe um guia para o estabelecimento das condições degradantes que devem ser empregadas neste tipo de estudo, o que gera dúvidas sobre o quão extremas estas condições devem ser e sobre como desenvolver e validar um método indicativo de estabilidade. Espera-se que, no futuro, com a experiência adquirida pelas indústrias e pela academia, e com o desenvolvimento e publicação de estudos, um maior alinhamento seja atingido acerca desse assunto e, assim, seja possível delimitar melhor os parâmetros e publicar novas diretrizes.

Diante da globalização e da importância das relações comerciais entre os países, além da necessidade da publicação de normas para atender às novas demandas é importante também que as legislações estejam em consonância, a fim de facilitar as questões de exportação e importação de insumos e produtos farmacêuticos. Neste sentido, a conquista da ANVISA de uma vaga no comitê gestor do ICH coloca a agência em destaque, visto que é a única autoridade da América Latina a ocupar tal posição. Com isto, ganha em poder decisório junto ao ICH, além de adquirir o direito de participar das discussões e realizar proposições à Assembleia sobre temas prioritários para harmonização, supervisão dos grupos de trabalho, eleição de novos membros e treinamentos. Desta forma, os medicamentos registrados pela ANVISA atenderão aos requisitos daqueles registrados nos principais mercados internacionais. Assim, o nível de exigência para o registro dos medicamentos no Brasil será elevado, bem como o padrão de qualidade, que será equiparado aos padrões internacionais. Com isso, haverá melhoria da qualidade dos medicamentos brasileiros, além do aumento da competitividade para o mercado nacional e do favorecimento das relações comerciais no âmbito de medicamentos entre o Brasil e os demais países do mundo.

Com relação às técnicas utilizadas na avaliação da estabilidade de insumos e produtos farmacêuticos, é possível observar uma evolução relacionada à maior seletividade e detectabilidade das mesmas ao longo dos últimos quarenta anos. Entretanto, devido à possibilidade de separar vários analitos e à elevada precisão, a CLAE é a técnica mais recomendada e empregada no desenvolvimento de métodos indicativos de estabilidade. Uma tendência refere-se à redução do tempo de análise e da quantidade de resíduos gerados, o que pode ser obtido com a utilização de técnicas que proporcionam análises mais eficientes e rápidas, como é o caso da CLUE. Dentre os detectores utilizados, o DAD merece destaque, uma vez que uma das suas vantagens consiste em permitir a verificação da homogeneidade espectral do pico cromatográfico. Um outro aspecto importante trata-se da identificação dos produtos de degradação e, para isso, técnicas com elevada detectabilidade e que permitem a caracterização estrutural dos compostos formados, como a espectrometria de massas, apresentam elevada aplicabilidade, sendo os analisadores de alta resolução, os mais indicados.

Por outro lado, em relação ao uso de técnicas de caracterização em estudos de estabilidade de produtos farmacêuticos, percebe-se, pelos inúmeros trabalhos reportados nos últimos anos, que essas técnicas fornecem informações valiosas e com uma imensa riqueza de detalhes, quando empregadas em estudos de estabilidade de IFAs e medicamentos. Outro aspecto marcante observado é o emprego destas técnicas de forma integrada, já que isso possibilita a avaliação de diferentes propriedades, como térmicas, moleculares, estruturais, morfológicas e polimóficas que estão relacionadas direta ou indiretamente com a estabilidade. O polimorfismo, definido como a habilidade de uma substância existir em duas ou mais formas cristalinas no estado sólido, e cuja ocorrência é até certo ponto comum em IFAs, ganhou muito destaque nas últimas decadas, uma vez que pode influenciar diretamente nas propriedades de interesse farmacêutico. ${ }^{129,130}$ Isso ocorre porque diferentes arranjos cristalinos de um mesmo IFA apresentam diferentes padrões de interações intra e intermoleculares e consequentemente diferentes energias de rede. Tal fato resulta em variações das propriedades físico-químicas e farmacêuticas, que podem ir desde a solubilidade e biodisponibilidade até a estabilidade do IFA no medicamento. De uma forma geral, todas as técnicas de caracterização mencionadas nesta revisão, são empregadas nos estudos de polimorfos visando estabelecer a sua possível influência na estabilidade de IFAs e medicamentos. ${ }^{131}$

Ainda que todos esses avanços no campo da pesquisa sejam notórios, a menção a essas técnicas de caracterização nas legislações e guias nacionais e internacionais relacionados à estabilidade ainda é muito discreta. Nesse sentido, espera-se que as próximas normas a serem publicadas sobre estabilidade envolvendo produtos farmacêuticos comecem a exigir ou pelo menos mencionem a utilização de algumas dessas técnicas, na tentativa de auxiliar a implementação e uso das mesmas na rotina dos laboratórios farmacêuticos.

\section{CONCLUSÃO}

O estudo de estabilidade de insumos e produtos farmacêuticos constitui um parâmetro de grande importância não apenas no que diz respeito aos aspectos legais, abrangendo as questões relativas ao registro e pós-registro, mas também quanto às questões de saúde pública. Além disso, o alinhamento das legislações dos diversos países é relevante para as relações comerciais. Neste sentido, a inserção da ANVISA no comitê gestor do ICH constitui um importante marco para os assuntos regulatórios que tratam de medicamentos no Brasil. A harmonização das normas pode expandir o comércio internacional, favorecendo a economia do país, além de alinhar o padrão de qualidade dos medicamentos produzidos no Brasil aos padrões internacionais.

Apesar de tamanha relevância, este tema é relativamente recente, especialmente em termos legais no Brasil. A evolução das técnicas analíticas confere ferramentas fundamentais para os estudos de estabilidade, proporcionando ganhos em termos de seletividade, detectabilidade, rapidez e até mesmo na redução da geração de resíduos, favorecendo questões ambientais, uma vez que a modernização das técnicas envolve o uso reduzido de solventes orgânicos, como acontece na CLUE.

Diante da constante evolução da legislação e das técnicas analíticas e de caracterização empregadas nos estudos de estabilidade de insumos e produtos farmacêuticos, este trabalho sintetiza os aspectos legais, bem como destaca a evolução de todas as técnicas direta ou indiretamente envolvidas, deixando claro qual é o atual cenário dos estudos de estabilidade e quais serão os desafios enfrentados nas próximas décadas, quanto à realização destes estudos no Brasil e no mundo.

\section{AGRADECIMENTOS}

Os autores agradecem à CAPES, CNPq e FAPEMIG pelo apoio financeiro.

\section{REFERÊNCIAS E NOTAS}

1. Farmacopeia Brasileira. 6 ed. Brasília: Agência Nacional de Vigilância Sanitária, 2019. 
2. WHO Guidelines on stability testing of pharmaceutical products containing well-established drug substances in conventional dosage forms, 1994. Disponível em: www.who.int, acessada em Abril 2020.

3. BRASIL. Ministério da Saúde. Agência Nacional de Vigilância Sanitária. RDC $n^{\circ} 45$, de 09 de agosto de 2012. Dispõe sobre a realização de estudos de estabilidade de insumos farmacêuticos ativos. Brasília: Diário Oficial da União, 2012.

4. Aulton, M. E. Delineamento de formas farmacêuticas. $2^{\mathrm{a}}$ ed., Artmed: São Paulo, 2001.

5. Zhang, K.; Pellett, J. D.; Narang, A. S.; Wang, Y.J.; Zhang, Y.T.; Trends in Anaytical Chemistry 2017, 101, 34

6. Wu, Y.; Levons, J.; Narang, A. S.; Ragahan, K.; Rao, V, M.; AAPS PharmSciTech. 2011, 12, 1248.

7. Bajaj, S.; Singla, D.; Sakhuja, N.; J. Appl. Pharm. Sci. 2012, 02, 129.

8. Carvalho, J. P.; Santos, A. S.; Sa, A. S.; Teixeira, C. S.; Nogueira, M. S.; Fármacos \& Medicamentos 2004, 8, 22.

9. BRASIL. Ministério da Saúde. Agência Nacional de Vigilância Sanitária. RDC no 318, de 06 de novembro de 2019. Estabelece os critérios para a realização de Estudos de Estabilidade de insumos farmacêuticos ativos e medicamentos, exceto biológicos, e dá outras providências. Brasília: Diário Oficial da União, 2019.

10. BRASIL. Ministério da Saúde. Agência Nacional de Vigilância Sanitária. RE no 01, de 29 de julho de 2005. Autoriza, ad referendum, a publicação do Guia para Realização de Estudos de Estabilidade. Brasília: Diário Oficial da União, 2005.

11. BRASIL. Ministério da Saúde. Agência Nacional de Vigilância Sanitária. RE no 398, de 12 de novembro de 2004. Determina a publicação do Guia para Realização de Estudos de Estabilidade. Brasília: Diário Oficial da União, 2004.

12. BRASIL. Ministério da Saúde. Agência Nacional de Vigilância Sanitária. RE no 485, de 19 de março de 2002. Determina a publicação do Guia para Realização de Estudos de Estabilidade. Brasília: Diário Oficial da União, 2002a.

13. ANVISA consquista vaga no comitê gestor do ICH. Portal ANVISA, 19 de nov. de 2019. Disponível em: <http://portal. anvisa.gov.br/noticias/-/asset_publisher/FXrpx9qY7FbU /content/ anvisa-conquista-vaga-no-comite-gestor-do-ich/219201?p_p_ auth=3Pacfyga\&inheritRedir ect=false \&redirect $=\mathrm{http}: / /$ portal . anvisa.gov.br/noticias\%3Fp_p_auth\%3D3Pacfyga\%26 p_p_id\%3D 101_INSTANCE_FXrpx9qY7FbU\%26p_p_lifecycle\%3D0\%26p_p_ state\%3Dnormal\%26p_p_mode\%3Dview\%26p_p_col_id\%3D_118_ INSTANCE_KzfwbqagUNdE_column-2\%26p_p_col_coun t\%3D2>, acessada em Abril 2020.

14. ICH Stability Testing of New Drug Substances and Products Q1A (R2), 2003. Disponível em: http://www.ich.org, acessada em Abril 2020.

15. Grimm, W.; Drug Dev. Ind. Pharm. 1993, 18, 2795.

16. ICH Photostability testing of new drug substances and products Q1B, 1996. Disponível em: http://www.ich.org, acessada em Abril 2020.

17. ICH Bracketing and Matrixing Designs for Stability Testing of Drug Substances and Products Q1D, 2002. Disponível em: http://www.ich. org, acessada em Abril 2020.

18. ICH Impurities: Guideline for residual solvents Q3C (R6), 2019. Disponível em: http://www.ich.org, acessada em Janeiro 2020.

19. ICH Guideline for elemental impurities Q3D (R1), 2019. Disponível em: http://www.ich.org, acessada em Janeiro 2020.

20. ICH Impurities in new drug substances Q3A (R2), 2006. Disponível em: http://www.ich.org, acessada em Abril 2020.

21. ICH Impurities in new drug products Q3B (R2), 2006. Disponível em: http://www.ich.org, acessada em Abril 2020.

22. BRASIL. Ministério da Saúde. Agência Nacional de Vigilância Sanitária. Guia n ${ }^{\circ} 04$, de 08 de dezembro de 2015. Guia para obtenção do perfil de degradação, e identificação e qualificação de produtos de degradação em medicamentos. Disponível em: http://portal.anvisa. gov.br/documents/10181/2738062/Perfil+e+produtos+de+degrada\%C 3\%A7\%C3\%A3o+em+medicamentos.pdf/c18a4857-9a5c-4292-a1bf07af6cad6902? v ersion=1.0, acessada em Abril 2020.

23. WHO Stability testing of active pharmaceutical ingredients and finished pharmaceutical products, 2017. Disponível em: www.who.int, acessada em Abril 2020.

24. BRASIL. Ministério da Saúde. Agência Nacional de Vigilância Sanitária. RE $n^{\circ} 560$, de 02 de abril de 2002. Determina a publicação do Guia para Realização de Estudos de Estabilidade. Brasília: Diário Oficial da União, 2002b.

25. BRASIL. Ministério da Saúde. Agência Nacional de Vigilância Sanitária. Informe Técnico n ${ }^{\circ} 1$ de 15 de julho de 2008. Brasília: Diário Oficial da União, 2008.

26. BRASIL. Ministério da Saúde. Agência Nacional de Vigilância Sanitária. Instrução Normativa ${ }^{\circ} 4$ de 11 de abril de 2007. Determina a publicação do Guia para a Realização de Estudos de Estabilidade para Medicamentos Dinamizados Industrializados. Brasília: Diário Oficial da União, 2007.

27. BRASIL. Ministério da Saúde. Agência Nacional de Vigilância Sanitária. RDC $n^{\circ} 50$ de 20 de setembro de 2011. Dispõe sobre as condições e procedimentos para a realização de estudos de estabilidade para o registro ou alterações pós registro de produtos biológicos. Brasília: Diário Oficial da União, 2011.

28. BRASIL. Ministério da Saúde. Agência Nacional de Vigilância Sanitária. RDC n ${ }^{\circ} 25$ de 14 de maio de 2013. Dispõe sobre as condições e procedimentos para a realização de estudos de estabilidade para o registro ou alterações pós registro de produtos biológicos. Brasília: Diário Oficial da União, 2013.

29. BRASIL. Ministério da Saúde. Agência Nacional de Vigilância Sanitária. RDC $\mathrm{n}^{\circ} 58$, de 20 de dezembro de 2013. Estabelece parâmetros para a notificação, identificação e qualificação de produtos de degradação em medicamentos com substâncias ativas sintéticas e semissintéticas, classificados como novos, genéricos e similares, e dá outras providências. Brasília: Diário Oficial da União, 2013.

30. BRASIL. Ministério da Saúde. Agência Nacional de Vigilância Sanitária. RDC n ${ }^{\circ}$ 53, de 04 de dezembro de 2015. Estabelece parâmetros para a notificação, identificação e qualificação de produtos de degradação em medicamentos com substâncias ativas sintéticas e semissintéticas, classificados como novos, genéricos e similares, e dá outras providências. Brasília: Diário Oficial da União, 2015.

31. BRASIL. Ministério da Saúde. Agência Nacional de Vigilância Sanitária. RDC n ${ }^{\circ} 171$, de 22 de agosto de 2017. Revisa a aplicabilidade da RDC 53, de 04 de dezembro de 2015, para alterações pós-registro e os prazos desta Resolução para produtos já registrados. Brasília: Diário Oficial da União, 2017.

32. BRASIL. Ministério da Saúde. Agência Nacional de Vigilância Sanitária. Perguntas \& Respostas. Assunto: RDC 53/2015 e Guia 04/2015. Disponível em: http://portal.anvisa.gov.br/resultado-debusca?p_p_lifecycle=0\&p_p_id=101\&p_p_col _count=1\&p_p_col_ id=column-1\&_101_assetEntryId=2885199\&p_p_state=maximize d\&_101_struts_action $=\% 2$ Fasset_publisher\%2Fview_content\&p_p_ mode=view\&_101_type=document, acessada em Abril 2020.

33. Amstalden, L.C. Validação e protocolos em análises químicas. Curso ministrado no CRQ IV Região - SP, 2010.

34. BRASIL. Ministério da Saúde. Agência Nacional de Vigilância Sanitária. RDC 166, de 24 de julho de 2017. Dispõe sobre a validação de métodos analíticos e dá outras providências. Brasília: Diário Oficial da União, 2017.

35. Mollica, J. A.; Ahuja, S.; Cohen. J. Pharm. Sci. 1978, 67, 443.

36. Bakshi, M.; Singh, S.; J. Pharm. Biomed. Anal. 2002, 28, 1011.

37. Al-Malaq, H. A.; Al-Majed, A. A.; Belal, F.; Anal. Lett. 2000, 33, 1961.

38. Archontaki, H. A.; Analyst 1995, 120, 2627. 
39. Baertschi, S. W.; Alsante, K. M.; Reed, R. A.; Pharmaceutical stress testing: predicting drug degradation, 2nd ed., Informa Healthcare: London, 2005.

40. Snyder, L. R.; Kirkland, J. J.; Glajch, J. L.; Practical HPLC method development, 2nd ed., Jonh Wiley \& Sons: New Yourk, 1997.

41. El Kousy, N. M.; Mikrochim. Act 1998, 128, 65.

42. Ashour, A.; Hegazy, M. A. M.; Moustafa, A. A.; Kelani, K. O.; Fattah, L. E. A.; Drug Test. Anal. 2009, 1, 327.

43. Mostafa, N. M.; J. Saudi Chem. Soc. 2010, 14, 341.

44. Treiber, L. R.; J. Chromatogr. 1986, 370, 139.

45. Schlemmer, W.; Kammerl, E.; J. Chromatogr. 1973, 82, 143.

46. The European Pharmacopoeia. 7 ed. Strasbourg: Directorate for the Quality of Medicines of the Council of Europe (EDQM), 2010.

47. British Pharmacopoeia. London: Her majesty's Stationary Office, 2014.

48. The united states pharmacopeia. USP 42.42 ed. Rockville: United States Pharmacopeial Convention, 2019.

49. Kulkarni, S. P.; Amin, P. D.; J. Pharm. Biomed. Anal. 2000, 23, 983.

50. Agrawal, H.; Kaul, N.; Paradkar, A. R.; Mahadik, K. R.; Talanta. 2003, $61,581$.

51. Damle, M. C.; Topagi, K. S.; Bothara, K. G.; Acta Chromatogr. 2010, 22, 433.

52. Michail, K.; Daabees, H. M.; Beltagy, Y.; Abdel-Khalek, M.; Khamis, M. M.; J. Chem. 2013, 2013, 1.

53. Sadakwala, V. M.; Chauhan, R. S.; Shah, S. A.; Shah, D. R.; J. Chromatogr. Sci. 2016, 54, 70.

54. Rangari, S. G.; Raut, N. A.; Dhore, P. W.; Curr. Pharm. Anal. 2019, 15, 273.

55. Dixit, R. P.; Barhate, C. R.; Nagarsenker, M. S.; Chromatographia 2008 , $67,101$.

56. Ho, C.; Chen, G.-L.; J. Food drug Anal. 1996, 4, 271.

57. Diego, M.; Godoy, G.; Mennickent, S.; Godoy, R.; Quim. Nova. 2011, $34,450$.

58. Panditrao, V. M.; Sarkate, A. P.; Sangshetti, J. N.; Wakte, P. S.; Shinde, D. B.; J. Braz. Chem. Soc. 2011, 22, 1253.

59. Ruela, A. L. M.; Santos, M. G.; Figueiredo, E. C.; Pereira, G. R.; J. Braz. Chem. Soc. 2014, 25, 2094.

60. Cione, A. P. P.; Liberale, M. J.; Da Silva, P. M.; Quim. Nova. 2010, 33, 203.

61. Almeling, S.; Ilko, D.; Holzgrabe, U.; J. Pharm. Biomed. Anal. 2012 , $69,50$.

62. Singh, S.; Junwal, M.; Modhe, G.; Tiwari, H.; Kurmi, M.; Parashar, N.; Sidduri, P.; Trends Anal. Chem. 2013, 49, 71.

63. Kamal, A. H.; Ismail, N. S.; Mabrouk, M. M.; Bebawy, L. I.; Mekky, M. A.; J. AOAC Int. 2019, 102, 1125.

64. Wu, Y.; Biomed. Chromatogr. 2000, 14, 384.

65. Bernardi, R. M.; D’Avila, F. B.; Todeschini, V.; Andrade, J. M. M.; Fröehlicha, P. E.; Ana, M. B.; J. Braz. Chem. Soc. 2015, 26, 660.

66. Raju, B.; Ramesh, M.; Srinivas, R.; Raju, S. S.; Venkateswarlu, Y.; J. Pharm. Biomed. Anal. 2011, 56, 560.

67. Zhou, N.; Li, T.; Ai, L.; Guo, C.; Zhang, J.; Fu, S.; Wang, Q.; Acta Chromatogr. 2019, 31, 12.

68. Sharma, M.; Jawa, P. R.; Gill, R. S.; Bansal, G.; J. Braz. Chem. Soc. 2011, 22, 836 .

69. Reis, N. F. A.; de Assis, J. C.; Fialho, S. L.; Pianetti, G. A.; Fernandes, C.; J. Pharm. Biomed. Anal. 2016, 126, 103.

70. Coelho, A. S.; Chagas, C. E. P.; de Pádua, R. M.; Pianetti, G. A.; Fernandes, C.; J. Pharm. Biomed. Anal. 2017, 145, 248.

71. Urano, R. P. M.; Rodrigues, F. T.; Berlinck, R. G. S.; Quim. Nova. 2012, 35, 1198.

72. Zhou, J.; Zhang, L.; Wang, Y.; Yan, C.; J. Sep. Sci. 2011, 34, 1811.

73. Joseph, A.; Patel, S.; Rustum, A.; J Chromatogr Sci. 2010, 48, 607.

74. Sun, P.; Wang, X.; Alquier, L.; Maryanoff, C. A.; J Chromatogr A. 2008, $1177,87$.
75. Al-Sayah, M. A.; Rizos, P.; Antonucci, V.; Wu, N.; J. Sep. Sci. 2008, 31, 2167.

76. Guillarme, D.; Ruta, J.; Rudaz, S.; Veuthey, J. L.; Anal. Bioanal. Chem. 2010, 397, 1069.

77. Krishnaiah, C.; Reddy, A. R.; Kumar, R.; Mukkanti, K.; J. Pharm. Biomed. Anal. 2010, 53, 483.

78. Kumar, N.; Vaghela, B.; Reddy, P. S.; Sangeetha, D.; Quim. Nova. 2012, $35,827$.

79. Jamrógiewicz, M.; Wielgomas, B.; J. Pharm. Biomed. Anal. 2013, 76, 177.

80. Belal, T.; Awad T.; Clark, C. R.; J AOAC Int. 2009, 92, 1622.

81. Augsburger, L. L; Hoag, S. W.; Pharmaceutical Dosage Forms: Capsules, $1^{\text {st }}$ ed., CRC Press: New York, 2017.

82. Vippagunta, S.; R.; Brittain, H.G.; Grant, D. J. W.; Adv. Drug. Deliv. Rev. 2001, 48, 3.

83. Thakral, N. K.; Zanon, R. L.; Kelly, R, C.; Thakral, S.; J. Pharm. Sci. 2018, 107, 2969.

84. Chadha, R,; Bhandari S.; J. Pharm. Biomed. Anal. 2014, 87, 82.

85. Heinz, A.; Strachan C. J.; Gordon. K. C.; Rades. T.; J. Pharm. Pharmacol. 2009, 61, 971

86. Virtanen, T.; Maunu, S. L.; Int. J. Pharm. 2010, 394, 18.

87. Klang, V.; Valenta, C.; Matsko, N. B.; Electron Microscopy of Pharmaceutical Systems. Micron. 2013, 44, 45.

88. Blessy, M.; Patel, R. D.; Prajapati, P. N.; Agrawal, Y. K.; J. Pharm. Anal. 2014, 4,159

89. Phadnis, N. V.; Cavatur, R. K.; Suryanarayanan, R.; J. Pharm. Biomed. Anal. 1997, 15, 929.

90. Egusa, K.; Okazaki, F.; Schiewe. J.; Werthmann, U.; Wolkenhauer, M. I.; Drugs. R. D. 2017, 17, 413

91. Dash, A. K.; Suryanarayanan, R. I.; J. Pharm. Sci. 2002, 91, 983.

92. Giacovazzo, C.; Monaco, H. L.; Artioli G.; Fundamentals of Crystallography, 7th ed., Oxford University Press; New York, 2002.

93. Szabó, P.; Sebe, I.; Stiedl, B.; Kállai-Szabó, B.; Zelkó, R.; J. Pharm. Biomed. Anal. 2015, 115, 359.

94. Yonemochi, E.; Hoshino, T.; Yoshihashi, Y.; Terada, K.; Thermochim. Acta. 2005, 432, 70.

95. Docoslis, A.; Huszarik, K. L.; Papageorgiou, G. Z.; Bikiaris. D.; Stergiou, A.; AAPS J. 2007, 9, 361.

96. Rumondor, A. C. F.; Stanford, L. A.; Taylor, L. S.; Pharm. Res. 2009, 26, 2599.

97. Wegiel, L. A.; Mauer, L. J.; Edgar, K. J.; Taylor, L. S.; J. Pharm. Sci. 2013, 102, 171.

98. Ozawa, T.; Thermochim. Acta. 2000, 355, 35.

99. Bernal, C.; Couto, A. B.; Breviglieri, S. T.; Cavalheiro, E. T. G.; Quim. Nova. 2002, 25, 849.

100. Pereira, J. G.; Okumura, F.; Ramos, L. A.; Cavalheiro, E. T. G.; Nóbrega, J. A.; Quim. Nova. 2009, 32, 1661.

101. Chadha, R.; Arora, P.; Bhandari, S.; Bala, M.; Curr. Microsc. Contrib. Adv. Sci. Technol. 2012, 2, 1013.

102. Oliveira, M. A. D.; Yoshida, M. I.; Gomes, E. C. L.; Quim. Nova. 2011, 34, 1224.

103. Marini, A.; Berbenni, V.; Pegoretti, M.; Bruni, G.; Cofrancesco, P.; Sinistri, C.; Villa, M.; J Therm. Anal. Calorim. 2003, 73, 547.

104. Bruni, G.; Berbenni, V.; Milanese, C.; Girella, A.; Marini, A.; J. Therm. Anal Calorim. 2010, 102, 193.

105. Harding, L.; Qi, S.; Hill, G.; Reading, M.; Craig, D. Q. M.; Int. J. Pharm. 2008, 354, 149

106. Bugay, D. E.; Adv. Drug. Deliv. Rev. 2001, $48,43$.

107. Breitenbach, J.; Schrof, W.; Neumann, J.; Pharm. Res. 1999, 16, 1109.

108. Kaushal, A. M.; Chakraborti, A. K.; Bansal, A. K. F.; Mol. Pharm. 2008, $5,937$.

109. Zhou, G. X.; Ge, Z.; Dorwart, J.; Izzo, B.; Kukura, J.; Bicker, G.; Wyvratt, J.; J. Pharm. Sci. 2003, 92, 1058 
110. Saerens, L.; Dierickx, L.; Lenain, B.; Vervaet, C.; Remon, J. P.; Beer, T. D.; Eur. J. Pharm. Biopharm. 2011, 77, 158.

111. Andrews, G. P.; Abudiak, O, A.; Jones, D. S.; J. Pharm. Sci. 2010, 99, 1322.

112. Rantanen, J.; Antikainen, O.; Mannermaa, J. P.; Yliruusi, J.; Pharm. Dev. Technol. 2000, 5, 209.

113. Santos, M. D. S.; Colnago, L.; Quim. Nova. 2013, 36, 324.

114. Aguiar, M. R. M. P.; Gemal, A. L.; San Gil, R. A. D. S.; Quim. Nova 1999, 22, 553.

115. Bugay, D. E.; Pharm. Res. 1993, 10, 317.

116. Tishmack, P. A.; Bugay, D. E.; Byrn, S. R.; J. Pharm. Sci. 2003, 92, 441.

117. Aso, Y.; Yoshioka, S.; Kojima, S.; J. Pharm. Sci. 2000, 89, 408.

118. Schachter, D. M.; Xiong, J.; Tirol, G. C. Int. J. Pharm. 2004, 281, 89.

119. Shen, S.; Yao, J.; Shi, Y.; J. Pharm. Biomed. Anal. 2014, 89, 118-121.

120. Peng, S. X.; Borah, B.; Dobson, R. L. M.; Liu, Y. D.; Pikul, S.; J. Pharm. Biomed. Anal. 1999, 20, 75.

121. Peng, S. X.; Biomed. Chromatogr. 2000, 14, 430.

122. Rocha, A. B.; Kuminek, G.; Machado, T. C.; Rosa, J.; Rauber, G. S.; Borba, P. A.; Siedler S.; Stulzer, H. K.; Cuffini, S. L.; RodríguezHornedo, N.; Cardoso, S. G.; Quim. Nova. 2016, 39, 1112.
123. Duggirala, N. K.; Perry, M. L.; Almarsson, Ö.; Zaworotko, M. J.; Chem. Commun. 2016, 52, 640.

124. Duggirala, N. K.; Smith, A. J.; Wojtas, Ł.; Shytle, R. D.; Zaworotko, M. J.; Cryst. Growth. Des. 2014, 14, 6135.

125. Diniz, L. F.; Carvalho-Jr, P. S. C.; de Melo, C.; Ellena, J.; Cryst. Growth. Des. 2017, 17, 2622.

126. Schaffazick, S. R.; Guterres, S. S.; Freitas L. L.; Pohlmann, A. R.; Quim. Nova. 2003, 26, 726.

127. Elsabahy, M.; Wooley, K. L.; Chem. Soc. Rev. 2012, 41, 2545.

128. Lu, H.; Wang, J.; Wang, T.; Zhong, J.; Bao, Y.; Hao, H.; J. Nanomater. 2016, 2016, 1

129. Vippagunta, S. R.; Brittain, H. G.; Grant, D. J. W.; Crystalline solids. Advanced Drug Delivery Reviews. 2001, 48, 3.

130. Brittain, H. G. Em Polymorphism in pharmaceutical solids; Brittain, H. G., ed.; CRC Press: New York, 2016, cap. 1.

131. Hilfiker, R.; Blatter, F.; Von Raumer, M. Em Polymorphism in the pharmaceutical industry; Hilfiker, R., ed.; Wiley: New York, 2006, cap.1. 